\title{
What Determines the Future Ecological Risks of Wastewater Discharges in River Networks: Load, Location or Climate Change?
}

\author{
Soohyun Yang, ${ }^{1, *}$, Olaf Büttner1, Rohini Kumar², Stefano Basso ${ }^{3}$, and \\ Dietrich Borchardt ${ }^{1}$
}

${ }^{1}$ Helmholtz-Centre for Environmental Research - UFZ, Department of Aquatic Ecosystem Analysis and Management, Magdeburg, Germany

${ }^{2}$ Helmholtz-Centre for Environmental Research - UFZ, Department of Computational HydroSystem, Leipzig, Germany

${ }^{3}$ Helmholtz-Centre for Environmental Research - UFZ, Department of Catchment Hydrology, Halle/Saale, Germany

Corresponding author: Soohyun Yang (soohyun.yang@ufz.de)

\section{Key Points}

- A systematic, generic framework was developed to assess wastewater treatment plants causing ecological risks in river at catchment-scale.

- Smaller streams will face higher ecological risks for almost all load classes in future climate.

- Ammonium-nitrogen emission will pose the greatest ecological risk in the future, suggesting to revise related environmental regulations.

This paper is a non-peer reviewed preprint submitted to EarthArXiv.

It has been submitted for publication in Earth's Future journal, but has yet to be formally accepted for publication. 


\begin{abstract}
Over the last decades, treatment of domestic wastewater promoted by environmental regulations have reduced human health risks and improved water quality. However, ecological risks caused by effluents of wastewater treatment plants (WWTPs) discharged into rivers still persist. Moreover, the evolution of these ecological risks in the future is intimately related to effects of changing climate, especially regarding streamflow in receiving rivers. Here, we present a systematic and transferable framework for assessing the ecological risks posed by individual WWTP-effluents at the catchment-scale. The framework combines the size-class k of WWTPs, which is a proxy for load, with the location of their outflows in river networks, represented by its stream-order $\omega$. We identify ecological risks by using three proxy indicators: the urban discharge fraction and the local-scale concentrations of each total phosphorous and ammonium-nitrogen discharged from WWTPs. About 3,200 WWTPs over three large catchments (Rhine, Elbe, and Weser) in Central Europe were analyzed by incorporating simulated streamflow for the most extreme projected climate change scenario. We found that WWTPs causing ecological risks in future prevail in lower stream-orders, across almost all size-classes. Distinct patterns of ecological risks are identified in the k- $\omega$ framework for different indicators and catchments. We show that, as climate changes, intensified risks are especially expected in lower stream-orders receiving effluents of intermediate size WWTPs. We discuss implications of our findings for prioritizing WWTPs advancement and urging updates on environmental regulations. Further applications of the k- $\omega$ framework are discussed to help achieving global long-term commitments on freshwater security.
\end{abstract}




\section{Introduction}

Human settlements require clean water in sufficient quantity with constant supply and at the same time produce continuous wastewater flows loaded with pathogens, organic and mineral matter, nutrients and pollutants (HDR, 2002). Exposure to household wastewater in living environments can directly endanger human health caused by waterborne diseases and accelerating its spread (Naik \& Stenstrom, 2012; Wolfe et al., 2018). Thus, collecting and draining wastewater from domestic sources were considered as key strategies to sanitizing residential areas, resulting in $\sim 60 \%$ connection of recent global population to sewer systems (WWAP, 2017). As the basic needs for human health have been satisfied, larger-scope environmental problems induced by untreated wastewater releases have been addressed and resolved to mitigate water quality impairment, protect aquatic ecosystems integrity, and further ensure sufficient freshwater availability (Viessman et al., 2009; EEA, 2015; Arden \& Jawitz, 2019). Centralized wastewater treatment systems, such as municipal wastewater treatment plants (WWTPs), have played major and significant roles in accomplishing these complex and long-term societal and environmental challenges. Jones et al. (2021) estimate that as of 2015 about $52 \%$ of worldwide municipal and manufacturing wastewater is released to the environment after treatment processes, with values ranging from $\sim 16 \%$ in Sub-Saharan Africa to $\sim 86 \%$ in Western Europe. Over the coming decades, construction of new WWTPs is expected to meet targets to halve untreated wastewater discharges by 2030 under the Sustainable Development Goal (SDG) Target 6.3 formulated by the United Nations (UN, 2015). In addition, the needs for extended wastewater collection and treatment will be amplified due to continuous increase of human-produced wastewater followed by substantial growth of global population and its demand for water which is projected to increase of $50 \%$ by 2030. (UN, 2016).

In the course of the creation of nationwide wastewater infrastructures over time, nationalscale and international regulatory standards for effluents from WWTPs have been implemented over the recent decades, such as the EU Urban Waste Water Treatment Directive (UWWTD) (EEC, 1991) and the US Clean Water Act (USEPA, 1972). These regulations focused on end-of-pipe treatments which do not guarantee that a good-status of the aquatic ecosystem is achieved in many receiving water bodies (Büttner et al., 2020). This is mainly attributed to the fact that the environmental regulations for WWTP-effluents are lacking a systematic and site-specific 
incorporation of the properties and sensitivities of receiving bodies, such as hydrological flow conditions and spatial interference of wastewater discharges (Freni et al., 2010, Yang et al., 2019b). For example, despite remarkable reduction of nutrient loads discharged from European WWTPs in the recent few decades, point-source nutrient loads still pose local and regional scale problems regarding water quality and ecological impairments in Central Europe (Yang et al., 2019b; Büttner et al., 2020). Besides the conventional pollutants for which release regulations are already established, newly emerging contaminants discharged from WWTPs without current-applied regulations have additionally jeopardized the health of river ecosystems downstream of WWTP outlets, by increasing ecotoxicological risks, altering macroinvertebrate community composition, and losing species biodiversity (Gücker et al., 2006; Rice \& Westerhoff, 2017; Weitere et al., 2021). To assess environmental security of WWTP-effluents, a more comprehensive perspective which includes their impacts on the water quality of receiving river courses is needed. At global-scale, identifying and improving WWTPs causing significant ecological risks to receiving water bodies are indispensable requirements in successfully undertaking international commitments for protecting water quality and aquatic ecosystems with long-term but legally binding schedule, such as the UN SDGs and the EU Water Framework Directive (WFD) (European Commission, 2000).

With the aforementioned emission to receiving water perspective, changing climate conditions should be taken into account for assessing ecological risks of treated wastewater discharged via WWTPs under expected global warming. Increasing trends of continuous heatwaves and hot weather have prompted greater water usage of people to cope with heat by more frequently washing and cooling private and public fields (USEPA, 2015; EC \& EEA, 2020). Unprecedented heatwaves during last few decades have sparked record-breaking amount of daily water use in Europe (BBC, 2018; Lomax, 2021), in North America (Glassman, 2018; Labbe, 2021), and in Australia (Wells, 2014; Pearlman, 2018). Thus, regarding the emission, the adaptive behaviors of sweltering people are likely to augment the mass flux of water and pollutants discharged from WWTPs. In terms of the receiving water perspective, climate-related hydrological regimes of receiving rivers play crucial roles in determining the ecological risk-status of WWTPemissions. Lower magnitude of river flow provides less dilution capacity, resulting in higher fraction of WWTP-effluents in receiving streams and likely more direct exposure of people to anthropogenic pollutants in recreational places (Yang et al., 2019b; Siddiqui et al., 2020). In addition, the persistence of drier hydrological regimes results in prolonged residence time for 
solutes or particulate matters from WWTPs in river water columns. Consequently, undesirable ecological status such as excessive algal blooms or fish deaths can be more easily observed along rivers (Ritz \& Fischer, 2019; Kamjunke et al., 2021; Sheldon et al., 2021). Such extreme meteorological and hydrological conditions are expected to be more frequent under climate change (Stott, 2016; Hari et al., 2020; Hulley et al., 2020), thus calling for implementation of WWTPtechnology adaptation to changing climate that shall be accompanied by an ecological risk assessment of WWTP-effluents.

In this context, our aim is to develop a systematic, generic and transferable framework to assess ecological risks of WWTP-effluents and inform improvement of environmental guidelines across river basins in any climate zone. We envision this framework to be applicable under future scenarios of growing population, increasing wastewater production and WWTP construction, climate changes and their cascading impacts on human usage of water resources and hydrological regimes of receiving rivers. This study focuses on presenting the framework's fundamental principles, application, and implications under an extreme scenario for climate change. To this end, we selected the Rhine, Elbe, and Weser Rivers in Central Europe. The Rhine and Elbe have similar drainage area but significantly contrasting properties regarding climate (Marx et al., 2018; Thober et al., 2018), hydrological responses (Pfeiffer \& Ionita, 2017; Ionita \& Nagavciuc, 2020), matter transport from land to river (Hoffmann et al., 2020; Li et al., 2020), and river ecosystem responses (Hardenbicker et al., 2014; Hardenbicker et al., 2016). They also display notably similar characteristics in the hierarchical scaling patterns of the coupled human-WWTPs distribution across river networks (Yang et al., 2019a), see Section 2.1 for details of the study areas. Specifically, we employed a stream-ordering scheme that systematically characterizes the hierarchical structure of river networks (Horton, 1945; Strahler, 1957), and synthesized two independent geo-spatial datasets (i.e., WWTP-discharge locations and its receiving river streams) and modelled streamflow data under a projected extreme climate, to address the following questions:

- How will the impact of WWTP-effluents on ecological risks in receiving rivers develop under climate change?

- How would the impacts be different among large catchments in Central Europe? 
- How can a systematic, generic, and transferable framework be formulated to facilitate a quantitative and spatially explicit risk assessment of adverse impacts in aquatic ecosystems at the catchment-scale?

\section{Data}

\subsection{Study river basins}

This study focuses on three large river basins in Central Europe: the Rhine, the Elbe, and the Weser, with respective total drainage area of $\sim 185 \mathrm{~K}, \sim 144 \mathrm{~K}$, and $\sim 46 \mathrm{~K} \mathrm{~km}^{2}$ (Table 1), which were selected based on the following rationale. First, the fraction of people connected to WWTPs is overall high (>90\%) in Central European countries compared to other European regions (EEA, 2020b). Furthermore, WWTPs which apply the most stringent tertiary treatment processes serve at highest rate ( $77 \%$ ) people residing in Central Europe (EEA, 2020b). Second, several countries located in the select three river basins have sufficient similarities in lifestyle and water resources usage patterns of residents (EurEup, 2020). The strong commonalities in the degree of urban sanitary infrastructure, the level of advanced technology utilized in WWTPs and socio-economic conditions enable to minimize inherent uncertainty in international-scale metadata analyses. Lastly, river water bodies in Central Europe mostly characterized as continental and maritime climate zones are generally expected to experience the least changes in hydrologic conditions across Europe simulated under projected global warming scenarios (e.g., Marx et al., 2018; Thober et al., 2018). Note that here we limited our analyses for the three catchments to drainage areas in Germany, Czech Republic, and the Netherlands, resulting in a coverage of $61 \%, 99 \%$, and $100 \%$ (the Rhine, the Elbe, and the Weser, respectively; Table 1), because of constraints in the availability of WWTP metadata (see Sec. 2.2).

We used freely available EU Hydro dataset to indicate network configurations of the Rhine, the Elbe, and the Weser Rivers (EEA, 2020a). The EU Hydro river networks and the corresponding catchment boundaries are initially derived from EU Digital Elevation Models, and verified through comparison to photo-interpreted river networks provided by all 39 countries involved in the European Environmental Agency (EEA). To characterize the structural hierarchy of the select river networks, we referred to the metric of Horton-Strahler stream-orders $\omega$ (Horton, 1945) included 
in the EU Hydro dataset. All three catchments finally have $7^{\text {th }}$-order streams draining to the North Sea (Table 1). Furthermore the EU Hydro data set builds the basis for graph theory based networks that are used to calculate cumulative effects. 
Table 1. Characteristics for the study river basins

\begin{tabular}{|c|c|c|c|c|}
\hline & & \multicolumn{3}{|c|}{ River basin } \\
\hline Characteristic & Unit & Rhine & Elbe & Weser \\
\hline Total basin area ${ }^{\mathrm{a}, \mathrm{b}}$ & {$\left[\mathrm{km}^{2}\right]$} & 185,260 & 148,242 & 46,306 \\
\hline Source ${ }^{a, b}$ & {$[-]$} & Southeastern Swiss Alps & $\begin{array}{l}\text { Northern Czech Giant } \\
\text { Mountains }\end{array}$ & Central German highlands \\
\hline Mouth ${ }^{\mathrm{a}, \mathrm{b}}$ & {$[-]$} & North Sea in the Netherlands & $\begin{array}{l}\text { North Sea at Cuxhaven } \\
\text { (Germany) }\end{array}$ & $\begin{array}{l}\text { North Sea at northern } \\
\text { Bremen (Germany) }\end{array}$ \\
\hline $\begin{array}{l}\text { Mainstem length from } \\
\text { source to mouth }{ }^{a, b, c}\end{array}$ & {$[\mathrm{~km}]$} & 1,250 & 1,094 & 700 \\
\hline Total population ${ }^{\mathrm{a}, \mathrm{b}, \mathrm{c}}$ & [million people] & 58 & 25 & 8.4 \\
\hline Spanning countries ${ }^{\mathrm{a}, \mathrm{b},{ }^{*} 1}$ & {$[-]$} & $\begin{array}{l}\text { Germany (55); Swiss (18); France } \\
\text { (13); } \\
\text { The Netherlands (6); } \\
\text { Austria; Belgium; Italy; } \\
\text { Liechtenstein; Luxemburg }\end{array}$ & $\begin{array}{l}\text { Germany (66); } \\
\text { Czech Republic (33); } \\
\text { Austria; Poland }\end{array}$ & Germany (100) \\
\hline Climate zone ${ }^{a, b}$ & {$[-]$} & $\begin{array}{l}\text { Maritime in the west (dominated); } \\
\text { Continental in the southeast }\end{array}$ & $\begin{array}{l}\text { Maritime in the northwest; } \\
\text { Continental in the southeast } \\
\text { (dominated) }\end{array}$ & $\begin{array}{l}\text { Maritime in the north; } \\
\text { Continental in the southeast } \\
\text { (almost equal) }\end{array}$ \\
\hline $\begin{array}{l}\text { Mean and range of annual } \\
\text { precipitation a,c,d }\end{array}$ & [mm/year] & $945(500 \sim 3500)$ & $659(450 \sim 1600)$ & $780(600 \sim 1100)$ \\
\hline Mean annual discharge ${ }^{\mathrm{c}, \mathrm{d}, \mathrm{e}}$ & {$\left[\mathrm{m}^{3} / \mathrm{s}\right]$} & $\begin{array}{l}2300 \text { at Emmerich, close to the } \\
\text { Dutch-German border }\end{array}$ & 861 at Cuxhaven, Germany & $\begin{array}{l}371 \text { at Intchede located at } \\
\text { most downstream without } \\
\text { tidal effect }\end{array}$ \\
\hline
\end{tabular}

Note: ${ }^{\mathrm{a}}$ Uehlinger et al. (2009); ${ }^{\mathrm{b}}$ Pusch et al. (2009); ${ }^{\mathrm{c}}$ Yang et al. (2021); ${ }^{\mathrm{d}}$ Pfeiffer \& Ionita (2017); ${ }^{\mathrm{e}}$ Hardenbicker et al. (2016); *1: Values in parentheses indicate $\%$ of each country constituting the total basin area. Note that the cases of $>5 \%$ are presented here. 


\subsection{Wastewater treatment plants}

Member countries of the EU are mandatorily responsible for reporting all WWTPs with population equivalents $(\mathrm{PE})>2000$ and their properties to the EU under the UWWTD $(\mathrm{EC}, 1991)$. Note that WWTPs with PE $\leq 2000$ can be voluntarily reported. PE is a normal established proxy of total sanitary flows from people connected to each WWTP via sewer systems and non-sanitary flows such as urban storm water runoff. PE magnitude is estimated by per-capita mean loading equivalents for biochemical oxygen demand or nutrients (nitrogen or phosphorus). For example, one $\mathrm{PE}$ is considered as organic biodegradable load having a 5-day biochemical oxygen demand of $60 \mathrm{~g}$ per day (EEC, 1991). The EEA organizes the reporting process of WWTPs every two years and makes the data publicly available (EEA, 2019). We used the latest dataset published in the year 2016.

Since there are no compatible standards to categorize WWTPs over Europe, all WWTPs analyzed here were classified as five size-classes $k$ by following German regulations based on the PE magnitude: $k=1$ for $\mathrm{PE} \leq 1,000, k=2$ for $1,000<\mathrm{PE} \leq 5,000, k=3$ for $5,000<\mathrm{PE} \leq 10,000$, $k=4$ for $10,000<\mathrm{PE} \leq 100,000$, and $k=5$ for $\mathrm{PE}>100,000$ (https://www.gesetze-iminternet.de/abwv/anhang_1.html). The discharge points of the WWTPs were defined by overlapping the geospatial data of WWTPs with the EU Hydro river network. Note that WWTPs in Switzerland and France covering $\sim 31 \%$ of the Rhine catchment area were excluded from this study. Switzerland is not an EU member state and thus has no duty to report WWTP metadata. French WWTPs are reported with geospatial information but their nutrient output loads are missing. Overall, the total number of WWTPs analyzed for each catchment is respectively $\sim 1820$, $\sim 900$, and $\sim 480$ for the Rhine, Elbe, and Weser rivers (Fig. 1). About 5\% of total WWTPs have $<$ 2000 PE. 


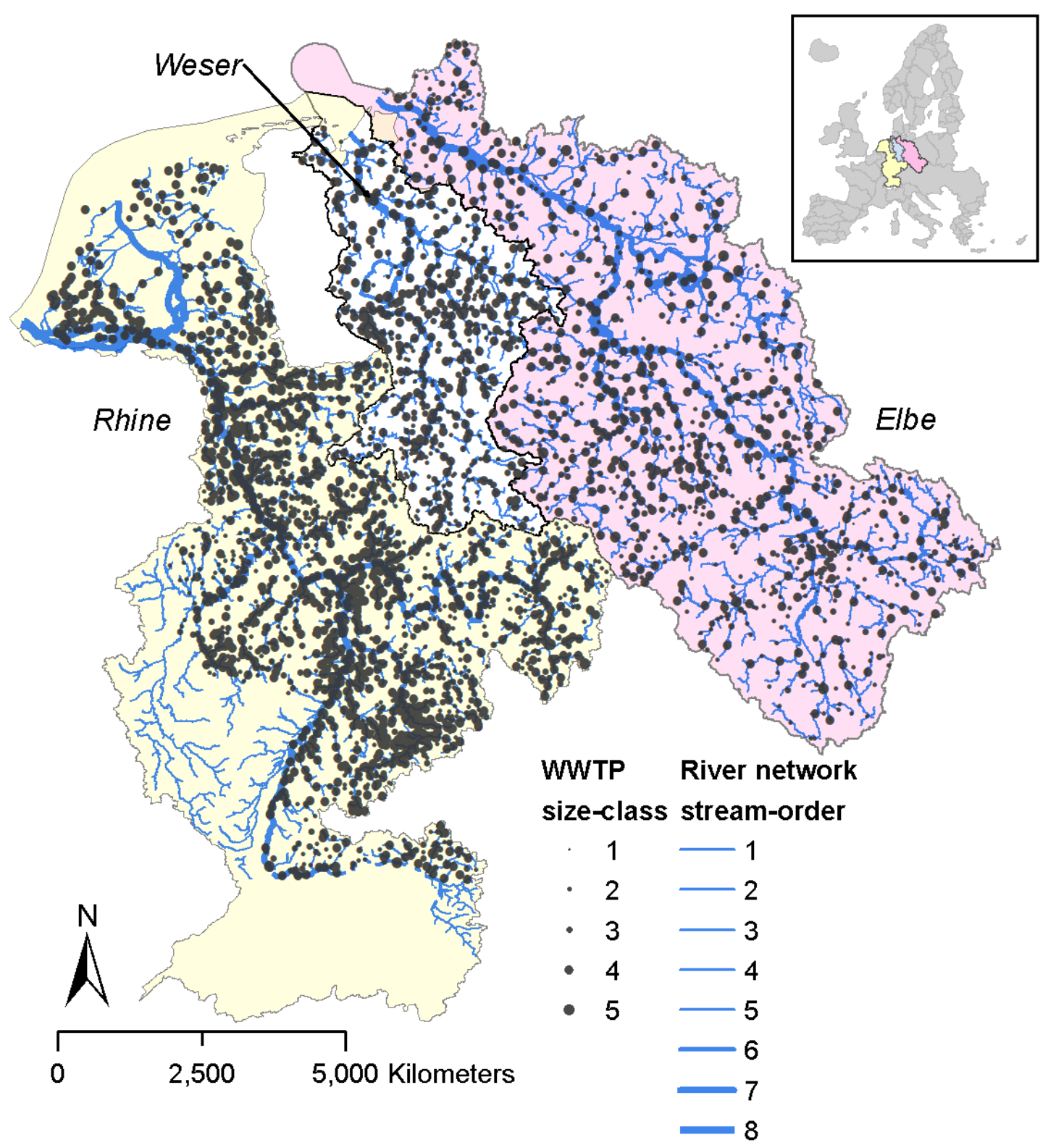

Figure 1. Spatial distribution of wastewater treatment plants (WWTPs) studied over Rhine, Elbe, and Weser catchments in Central Europe. Each drainage area of the three catchments is depicted with different background color. The upper right panel shows the geographical location of the studied catchments in the European continent. Black dots indicate WWTPs, and larger dots means greater WWTP size-class. Blue-lines are EU Hydro river networks of the three catchments. Thicker lines represent higher stream-order. 


\subsection{River discharge simulated under a climate change scenario}

River discharge data are prerequisite to estimate the impacts of WWTP-effluents on the water quantity and quality of receiving river bodies at local and regional scales. We used daily river discharge simulated over the entire Europe for a given climate condition (Marx et al., 2018) by the $5 \mathrm{~km}$-grid based mesoscale hydrological model (mHM) (Samaniego et al., 2010; Kumar et al., 2013). mHM simulations require hydro-metrological data inputs from the simulation results of a general circulation model (GCM) under a representative concentration pathway (RCP) reflecting the projected climate change conditions in the future. In this study, we employed the mHM results based on the GCM/RCP combination of GFDL-ESM2M/RCP8.5. Of three warming levels (1.5, 2 , and $3 \mathrm{~K}$ ) compared to pre-industrial conditions, we selected the $3 \mathrm{~K}$ warming level to consider

river discharge regimes resulting from the most severe expected climate change conditions. Sequentially, the simulated river discharge for the first 30-year period crossing the warming level of 3K (the years 2067-2096 - far future scenario) was compared to that of the reference period (the years 1971 - 2000 - historical scenario). Hydrological regimes for the selected periods were characterized (Text S1 and Fig. S1 in SI). More details on the basic assumptions, approaches and validations of the model simulations under projected climate change can be found in Marx et al. (2018); Thober et al. (2018); Samaniego et al. (2019).

\section{Methods}

\subsection{Assignment of river discharge data to WWTPs}

A receiving stream and its discharge data should be matched with each of the WWTPdischarge points to estimate effects of WWTP-effluents on river bodies. Given that the EU Hydro river networks, simulated discharge data, and WWTP metadata are independent data sources, developing an algorithm was needed to make spatial alignment across multiple datasets with different dimensions (i.e., point, line, and grid) and spatial resolutions possible. For example, two or more stream lines with different stream-orders can fall within the same grid cell used for the mHM discharge simulations. In general, only one of these multiple stream-orders should be 
accepted as the correct one, as suggested by the order of magnitude of the mHM-simulated river discharge.

Therefore, we developed an algorithm to identify the most reasonable river discharge simulation data for a stream or river reach receiving effluents of a given WWTP. The key principle was to minimize the assignment of stream-order from EU Hydro and those in mHM while simultaneously maximizing the spatial adjacency of a WWTP location and a mHM-grid. Details are given in Text $\mathbf{S 2}$ in SI.

\subsection{Urban wastewater discharge fraction}

We used the urban discharge fraction (UDF) as a proxy for estimating the impacts of treated wastewater discharged via WWTPs to their receiving river bodies at local-scales (Yang et al., 2019b). UDF is defined as the ratio between the discharged wastewater from WWTPs and the total water flux in their connected receiving stream or river:

$$
U D F_{\text {local }, i}(t)=\frac{Q_{U, i}}{Q_{U, i}+Q_{R, i}(t)}
$$

where $Q_{U, i}$ is the water flux discharged from the i-th WWTP, and $Q_{R, i}(t)$ indicates the time-series of river discharge at a given location receiving the effluents of the i-th WWTP. Here, $Q_{U, i}$ is calculated as a sum of wastewater from households and small industries $\left(Q_{H}\right)$, storm-water $\left(Q_{S W}\right)$, and sewer infiltration water $\left(Q_{S I W}\right)$. Taking the last two terms into account together as $Q_{S W}+Q_{S I W}$ $\sim Q_{H}$ (Büttner et al., 2020), the final expression of $Q_{U, i}$ is given as:

$$
Q_{U, i}=2 \cdot Q_{H, i}
$$

where $Q_{H, i}$ is estimated as a product of the population equivalent served by the i-th WWTP and the annual mean daily water usage per capita in Germany (123 1/day/person). Note that in this study $Q_{U, i}$ is dealt with as a constant over time under the assumption that daily per-capital water usage of people living in the three catchments would only change for sub-seasonal time periods under far future climates. By referring to temporally varying $Q_{R, i}(t), U D F_{\text {local }, i}(t)$ is calculated with 
a daily time-step $t$ for the i-th WWTP at the local-scale under the two climate scenarios. The value of UDF ranges from 0 to $100 \%$. A higher UDF value indicates a lower dilution capacity of the receiving river.

In addition to this local-scale assessment, we also estimated the basin-scale UDF at each discharging point of WWTPs by reflecting accumulated effluents of all upstream WWTPs along river flow paths. A graph theory based network grounded on the EU Hydro river network dataset was applied to identify upstream WWTPs for a given WWTP (i.e., WWTPs serving as nodes and river segments as edges). Indeed, the location of the i-th WWTP is regarded as a nested sub-basin outlet with a corresponding UDF $\left(U D F_{\text {basin, },}\right)$. Within the scope of this study, the complementary perspective enables horizontally expanded understanding of the adverse impacts of WWTP-driven pressures on river water quality. Thus, the value of $U D F_{b a s i n, i}$ is calculated as:

$$
\begin{gathered}
U D F_{b a \sin , i}(t)=\frac{Q_{b a \sin , U, i}}{Q_{\text {basin }, U, i}+Q_{R}(t)} \\
Q_{b a \sin , U, i}=\left(\sum_{j<i} Q_{b a \sin , U, j}\right)+Q_{U, i}
\end{gathered}
$$

where the index $j$ denotes all WWTPs located upstream of the i-th WWTP, and thereby the effluents of individuals WWTPs $j$ are converged to the receiving river of the i-th WWTP. $Q_{R}(t)$ indicates temporal dynamics of river discharge at the outlet of the catchment.

\subsection{Local-scale mixing concentrations of pollutants in receiving waters}

We focused on the two key pollutants discharged from WWTPs, total phosphorous $(\mathrm{P})$ and ammonium-nitrogen $(\mathrm{NH} 4 \mathrm{~N})$, whose values are established proxies for ecological risks in receiving river bodies (Ansorge et al., 2020). However, the approach can be applied to any other pollutants of known per capita loadings discharged from WWTPs. The local mixing concentration for the nutrients $\mathrm{C}_{Z}(Z=\mathrm{P}$ and $\mathrm{NH} 4 \mathrm{~N})$ is estimated as: 


$$
C_{Z, i}(t)=\frac{L_{Z, U, i}+L_{Z, R, i}(t)}{Q_{U, i}+Q_{R, i}(t)}
$$

where $L_{Z, U, i}$ indicates the loads of nutrient $Z$ discharged from the i-th WWTP, and $L_{Z, R, i}(t)$ means the in-stream loads of nutrient $Z$ at a direct upstream point before $L Z, U, i$ is mixed in a reach. For the local-scale of our interest, $L Z, R, i(t)$ is set as 0 to examine the sole impact of point-source nutrient loads discharged from WWTPs on water quality impairment (i.e., 'zero' background concentrations for nutrients in receiving river).

The value of $L_{Z, U, i}$ was yielded through the procedure detailed below. Firstly, the total influent nutrient loads to the i-th WWTP $(L Z, U, i, i n)$ was calculated as the product between PE and daily $\mathrm{Z}$ loads produced by one person (i.e., PE x LZ,person). We employed the value of $L$ z,person (1.8 gP/day/person, 11gN/day/person) estimated over Germany (ATV-DVWK, 2003; Nivala et al., 2018; Westphal et al., 2019). Next, we applied differences of treatment efficiency for $Z$ loads by size-classes $\left(\varepsilon_{Z, \mathrm{k}} ; \mathrm{Z}=\mathrm{P}\right.$ and $\left.\mathrm{N}\right)$. Finally, $L_{Z, U, i}$ for $\mathrm{NH} 4 \mathrm{~N}$ was estimated from total $\mathrm{N}$ loads (because of the lack of direct reference on per-capita NH4N loads production) by introducing the fraction of NH4N to total $N(N)$ in the effluents of WWTPs by size-classes $\left(\gamma_{\mathrm{k}}\right)$. Consequently, the resulting estimates of the i-th WWTP-discharged loads were $L_{Z, U, i, \text { in }} \mathrm{x}\left(1-\varepsilon_{Z, \mathrm{k}}\right)$ for $\mathrm{P}$ and $L_{Z, U, i, \text { in }} \mathrm{X}\left(1-\varepsilon_{Z, \mathrm{k}}\right) \mathrm{x}$ $\gamma_{k}$ for NH4N. Respective values of $\varepsilon_{Z, k}$ and $\gamma_{k}$ used in this study are given in Table 2 . The results and discussion presented in the main text are based on values of $\varepsilon$ and $\gamma$ respectively equal to their $10^{\text {th }}$ and $90^{\text {th }}$ percentiles. 
Table 2. Nutrient removal efficiency $(\varepsilon)$ and fraction of $\mathrm{NH} 4 \mathrm{~N}$ to total $\mathrm{N}$ effluent loads $(\gamma)$ by WWTPs size-classes

\begin{tabular}{|c|c|c|c|}
\hline \multirow{2}{*}{$\begin{array}{c}\text { WWTP } \\
\text { Size-class k* }\end{array}$} & \multicolumn{3}{|c|}{$\begin{array}{c}\text { Conservative scenario } \\
\left(\varepsilon=1^{\text {th }} \text { and } \gamma=\mathbf{9 0}^{\text {th }} \text { percentile }\right)\end{array}$} \\
\hline 1 & $\varepsilon_{\mathrm{k}}$ for P & $\varepsilon_{\mathrm{k}}$ for $\mathbf{~}$ & $\gamma_{\mathbf{k}}$ \\
\hline 2 & 0.3 & 0.38 & 0.6 \\
\hline 3 & 0.45 & 0.54 & 0.53 \\
\hline 4 & 0.67 & 0.7 & 0.24 \\
\hline 5 & 0.86 & 0.71 & 0.21 \\
\hline
\end{tabular}

*Note that the estimates of $\varepsilon$ and $\gamma$ were based on their corresponding data of the selected $\sim 5,560$ German WWTPs ( $\sim 62 \%$ of total $\sim 9,000$ WWTPs serving $\sim 96 \%$ of total residents) (DWA, 2019).

\subsection{The k- $\omega$ framework for risk assessment}

We applied a binary classification of WWTP 'Causing ecological risk' or 'Not causing ecological risk' (WWTP-CER or WWTP-not-CER) to classify each individual WWTP effluent regarding the proxy indicators $\mathrm{UDF}, \mathrm{CP}_{\mathrm{P}}$, and $\mathrm{C}_{\mathrm{NH} 4 \mathrm{~N}}$ in the three studied catchments. In this study, 'Causing ecological risk' for a given indicator is assigned when the probability of calculated proxy values is exceeding desirable thresholds, WWTP* ${ }_{\text {threshold }}$ (Fig. S2 in SI). Here, we selected two exemplary values of WWTP*threshold of $50 \%$ for median case $\left(\mathrm{WWTP}^{*}{ }_{50}\right)$. For a given WWTP* threshold, the same value was applied to all three catchments for both climate scenarios. Here, the presented results and discussion are based on the criterion of WWTP* ${ }_{50 .}$

The desirable criteria for the environmental variables were selected as the thresholds required to achieve surface water bodies with at least Good-Ecological-Status as set by the EU WFD (European Commission, 2000). The thresholds applied for the three variables are UDF* $=$ 
3.1\% (Büttner et al., 2020), $\mathrm{C}_{\mathrm{P}}^{*}=0.1 \mathrm{mgP} / \mathrm{L}$ (Heidecke et al., 2015), and $\mathrm{C}_{\mathrm{NH} 4 \mathrm{~N}} *=0.1 \mathrm{mgN} / \mathrm{L}$ (BMUB/UBA, 2014).

By catchments, the resultant binary risk-class for an environmental variable under a selected climate scenario is presented in a 2-dimensional domain consisting of stream-order $\omega$ on the abscissa and WWTP size-class $k$ on the ordinate, named as 'the $k$ - $\omega$ framework'. Individual grids in the $k$ - $\omega$ framework can contain any metric of interest, such as the number of WWTPs at risk or the fraction of at-risk-WWTPs out of total.

\section{Results and Discussion}

\subsection{Local-scale assessment of WWTPs causing ecological risk}

4.1.1 Predicted status in far future

For all three rivers, the number of "WWTPs causing ecological risk (WWTP-CER)" in far future was the highest for the NH4N indicator and the lowest for the TP indicator. (Fig. 2). WWTPCER for NH4N, UDF, and TP indicators accounted for respectively 40 50\%, 35 45\% and 25 33\% of total WWTPs in each river basin (Figs. 2a-2c). Distinctive differences of the fraction of WWTPCER for all three indicators were identified: the Weser exhibited the lowest fraction, whereas the Elbe and the Rhine had similarly higher fraction. The finding suggests that, in the Weser basin, partitioning residential communities served by their own WWTP and location of the WWTPs were better balanced to less compromise water quality of individual receiving streams affected by localscale WWTPs-effluents. Indeed, individuals WWTPs in the Weser served on average $\sim 13$ to $28 \%$ smaller PE ( 26K PE/WWTP) than those in the other two catchments. Furthermore, the Weser had $\sim 6 \%$ lower fraction of WWTPs in smaller streams $(\omega<3)$ than the other two.

None of the three indicators (NH4N, UDF, and TP) showed uniform distributions of WWTP-CER over the entire ranges of WWTP size-class $(k)$ and stream-order $(\omega)$ in the three rivers (Figs. 2d-2I). Rather, WWTP-CER for each indicator were strongly clustered in lower-order streams $(\omega<3)$ and spanned across almost all size-classes. In general, the fraction of WWTP-CER out of total for a given $k-\omega$ combination increased as $k$ and $\omega$ became greater and lower, respectively. The results indicated that smaller receiving streams were highly vulnerable to direct 
effluents of WWTPs, which inevitably related to impairment of river water quality and degradation of aquatic ecosystems integrity. This tendency has been noted previously: Yang et al. (2019b) show that smaller streams account for $\sim 90 \%$ of total streams for which local-scale mixing concentrations for total P and total $\mathrm{N}$ loads discharged from WWTPs in the Weser River exceed desirable concentration to achieve at least Good-ecological-status under steady-state median flow. Büttner et al. (2020) also show that across Germany linearly decreasing ecological status for increasing local-scale urban discharge fraction is significantly evident in low-order streams, whereas no dependence is found for higher-order streams. Moreover, Rice \& Westerhoff (2017) demonstrate that lower-order streams across the continuous US are more likely to be at higher risk up to 4 orders of magnitude for endocrine disrupting compounds discharged from WWTPs.

It was noteworthy that each indicator exhibited distinct distribution patterns of the WWTPCER in the $k$ - $\omega$ domain, despite the overall common character (i.e., clustering in higher $k$ - lower $\omega)$. For a given catchment, WWTP-CER for the UDF indicator were dominantly found in a wider range of $\omega$ (from 1 to 5 ) for intermediate and large sizes $(k=3 \sim 5)$ (Figs. 2d-2f). On the other hand, WWTP-CER for the NH4N indicator were more prominent in a relatively narrower range of $\omega$ (from 1 to 4 ) but extended to smaller size $(k=2 \sim 5)$ (Figs. 2j-2l). Remarkably, the dominance of the WWTP-CER for the TP indicator was manifested in the least extent of the $k-\omega$ domain (i.e., $k=2 \sim 5, \omega=1 \sim 2$ ). The existence of WWTP-CER with smaller $k$ for the NH4N and TP indicators was in good agreement with the absence of regulatory guidelines for the nutrients concentration discharged from smaller WWTPs $(k=1 \sim 3)$ (EEC, 1991). The fraction of WWTP-CER for all indicators decreased by increasing WWTP $^{*}{ }_{\text {threshold }}$ (Fig. S3 in SI). For instance, compared to WWTP $^{*}$, the lower threshold WWTP ${ }_{20}$ increased WWTP-CER by $\sim 15.5 \%$ (for UDF and TP) and $\sim 12 \%$ (for NH4N) on average over the three catchments. The fraction of WWTP-CER kept the highest for NH4N, and followed by UDF and TP. The additional WWTP-CER manifested themselves in the $k$ - $\omega$ domain as a gradual expansion of the range of $\omega$ affected (Fig. S4 in SI). While the expansion for water quality indicators (TP and NH4N) spanned across all size-classes, that for water quantity metric (UDF) occurred prominently in the largest size-class. The distinct patterns suggested different responses of water quantity and quality indicators to sensitivity of thresholds defining WWTP-CER. Accordingly, complementary examination of both aspects can assist a comprehensive assessment of WWTP-effluents effects on receiving rivers. 
a)

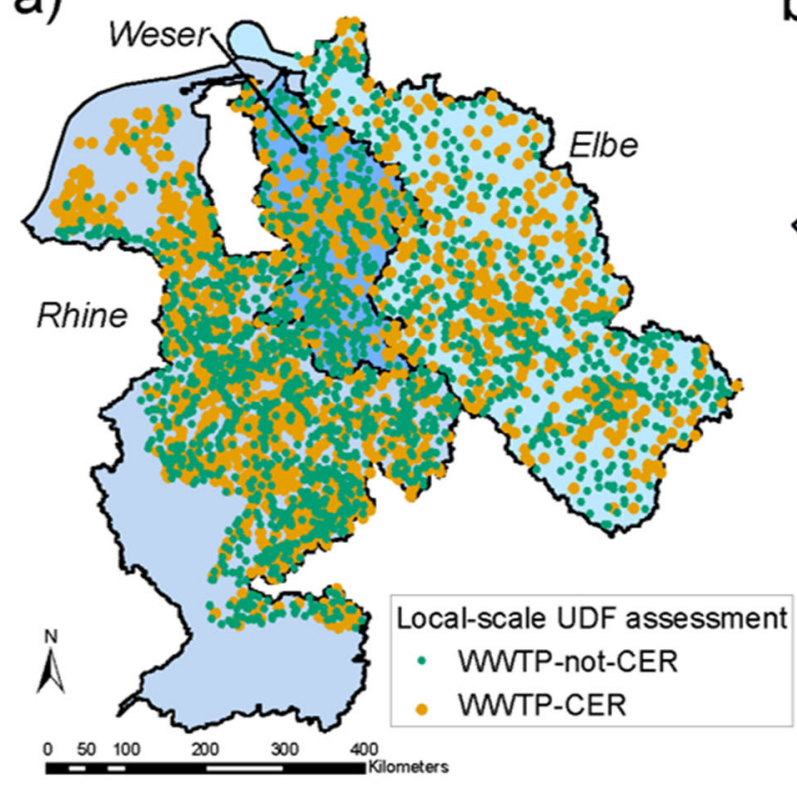

b)

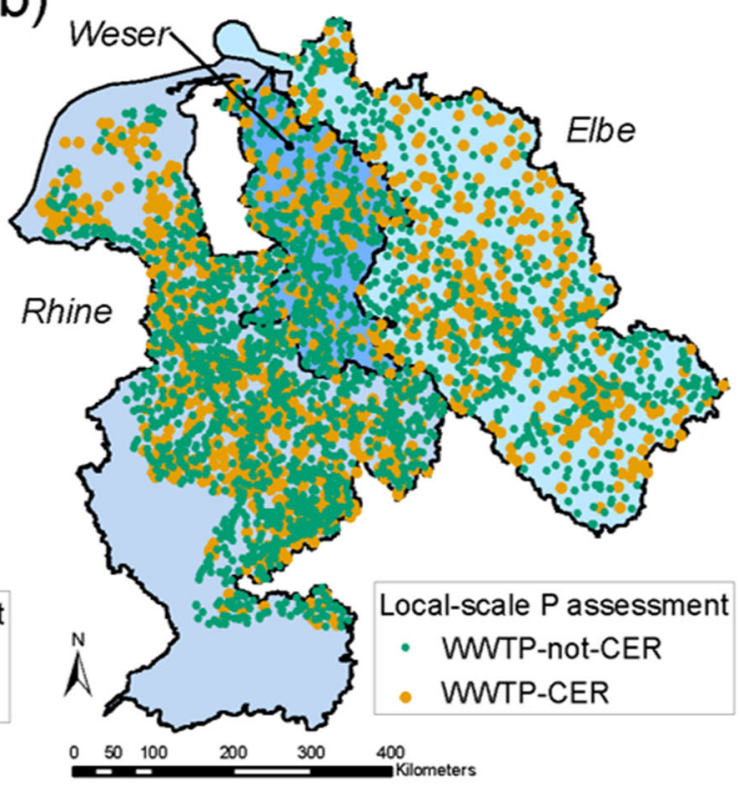

c)

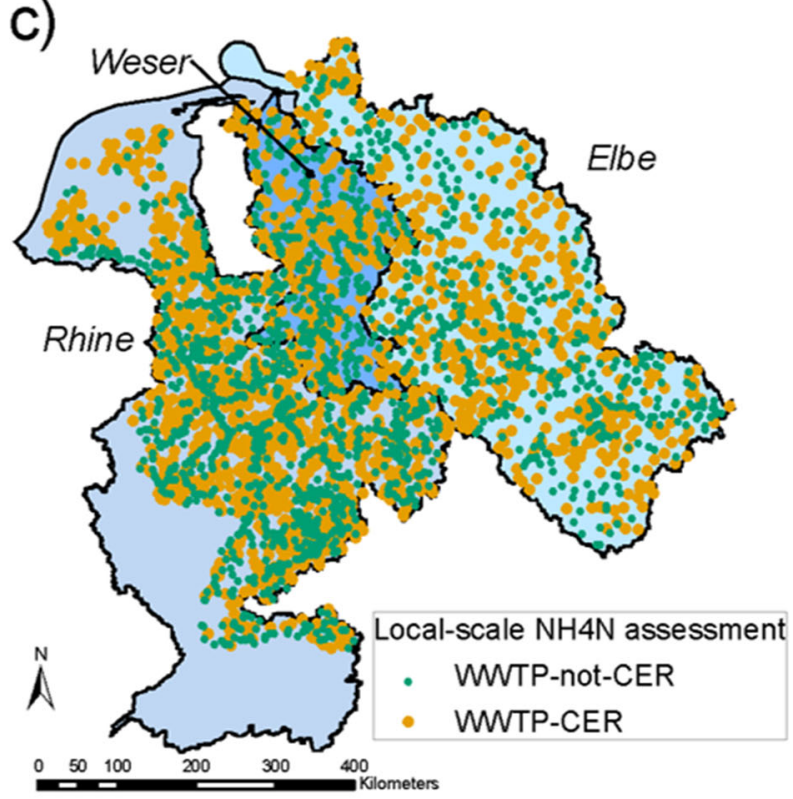

Figure 2. Spatial map and the associated k- $\omega$ framework representation under the threshold of WWTP* ${ }_{50}$ for all proxy indicators estimated from a given WWTP-effluent estimated with $\gamma=90$ th and $\varepsilon=10$ th percentiles at the local-scale under the far future scenario. (a-c) For the three river basins, the risk-assessments for UDF, P and NH4N concentrations at the local-scale are presented as the WWTPCER (Causing Ecological Risk) in orange and the opposite case in green. (d-l) The results of the risk-assessments shown in (a) to (c) are distributed by stream-order $\omega$ in the abscissa and by WWTP-size $\mathrm{k}$ in the ordinate. With the same color-codes of two status, WWTPCER $<50 \%$ of total is depicted as 2-D pie, and the opposite case as 3-D pie for three environmental indicators (rows) by each river basin (columns). 
d)

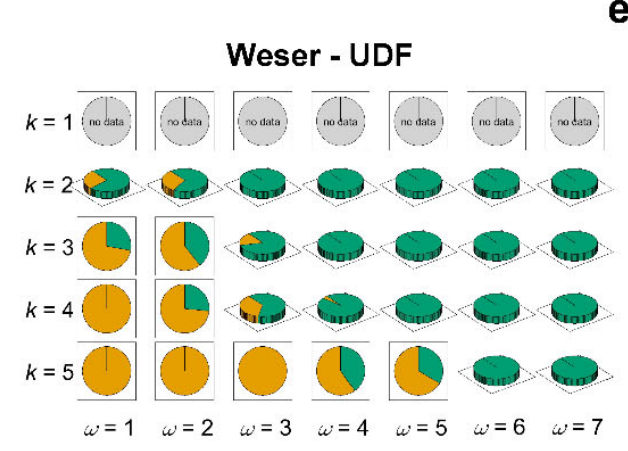

g)

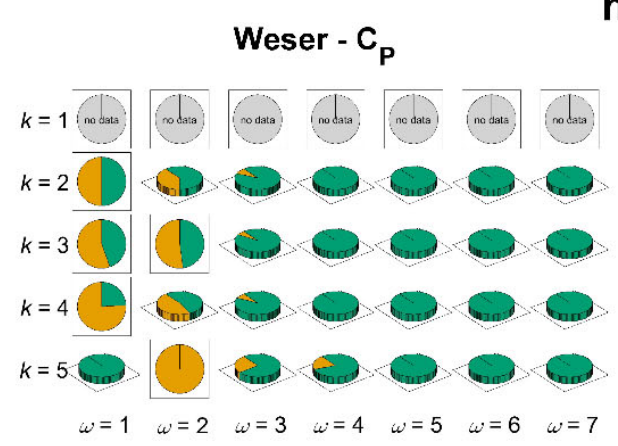

j)

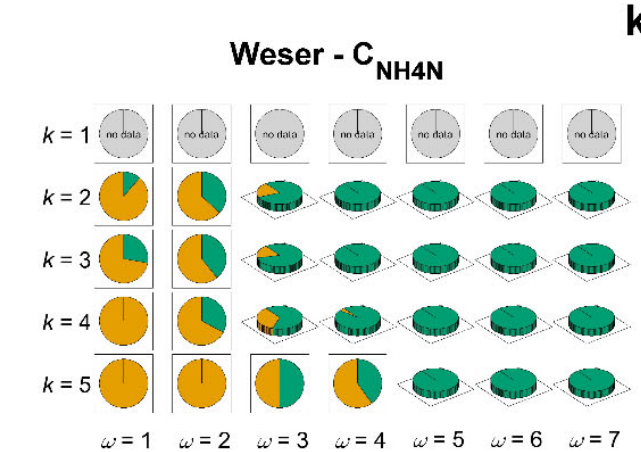

e)

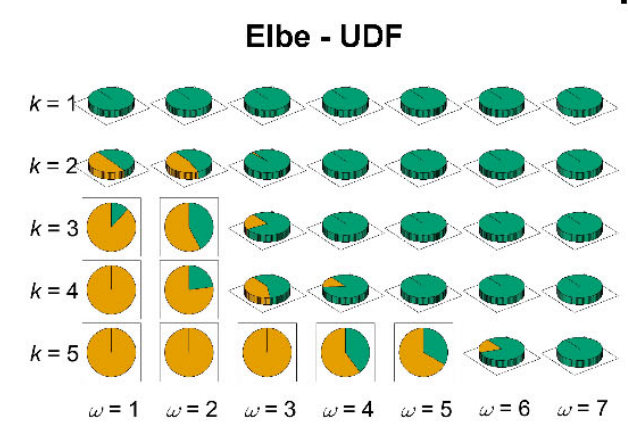

h)

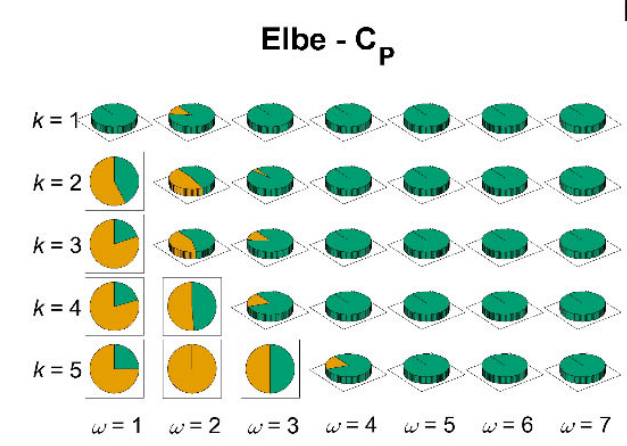

k)

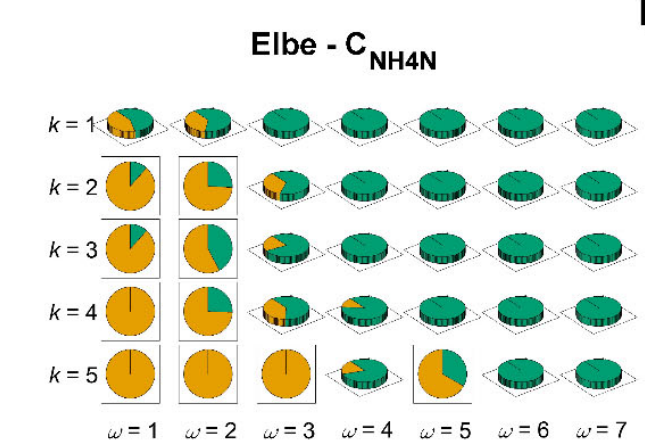

f)

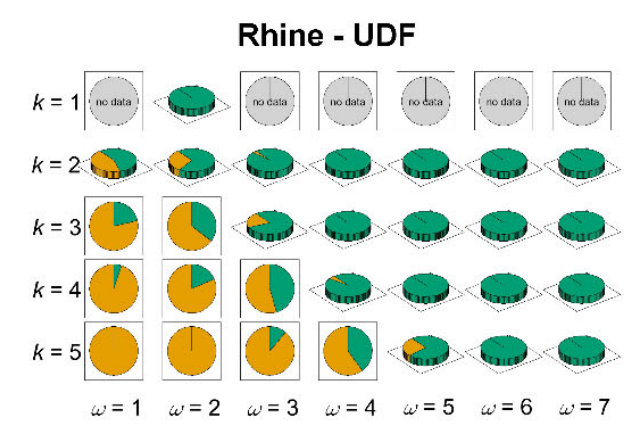

i)

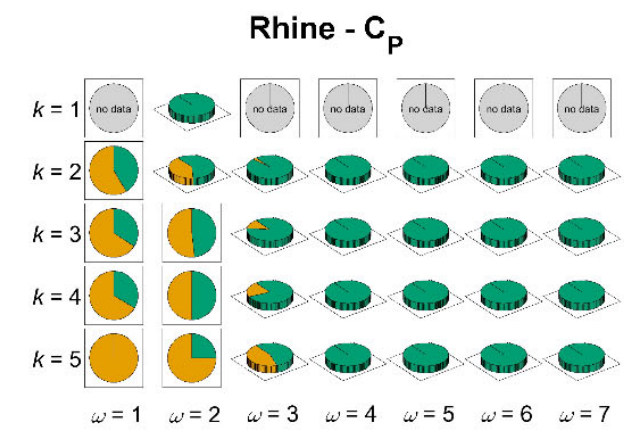

I)

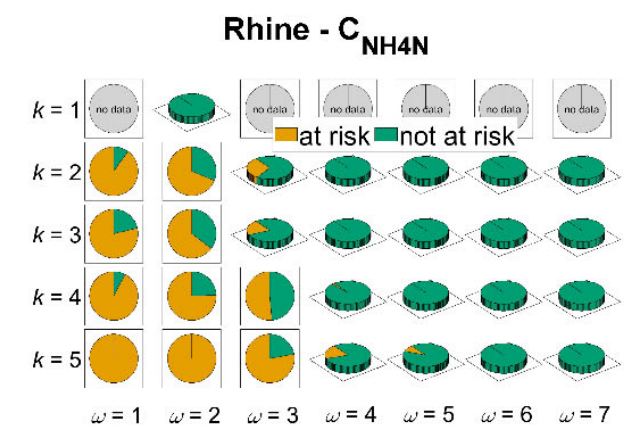

Figure 2. Continued. 


\subsubsection{Differences induced by climate change}

To understand the effects of climate-induced dynamics of streamflow on increasing WWTP-CER, we calculated the differences of the fraction for individual indicators between the two periods (Fig. 3). Most of the differences were found in smaller streams receiving effluents of intermediate-size WWTPs (i.e., $\omega<4, k=2 \sim 4$ ) for all three catchments. The common pattern revealed that the largest WWTPs already impaired small and intermediate streams during the wetter historical period due to insufficient dilution capacity. For all three indicators, the fraction of WWTP-CER in the far future mostly increased for the Elbe and Rhine, but decreased for the Weser. The trend was confirmed for lower values of WWTP* threshold (Fig. S5 in SI). Note that the lower number of WWTP-CER in the far future should not be interpreted as a result of wetter hydrological regime in the Weser, because the shape of entire flow duration curve affects the estimated exceedance probability (Text S3 and Fig. S6 in SI). Thus, the finding may be attributable to the less frequent occurrence of extreme dry streamflow in the far future in the Weser River. (Table 1). Basin-scale analyses of changes of hydro-meteorological properties and their linkage to the effects of WWTP-effluents on river water quality are worthy of future studies. 

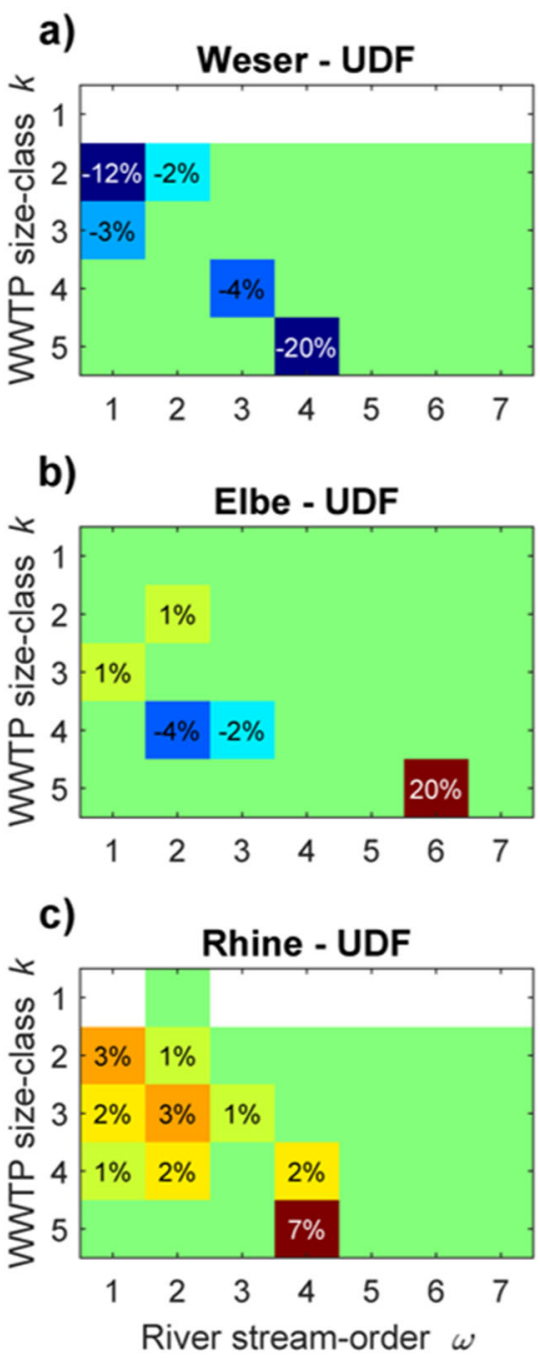
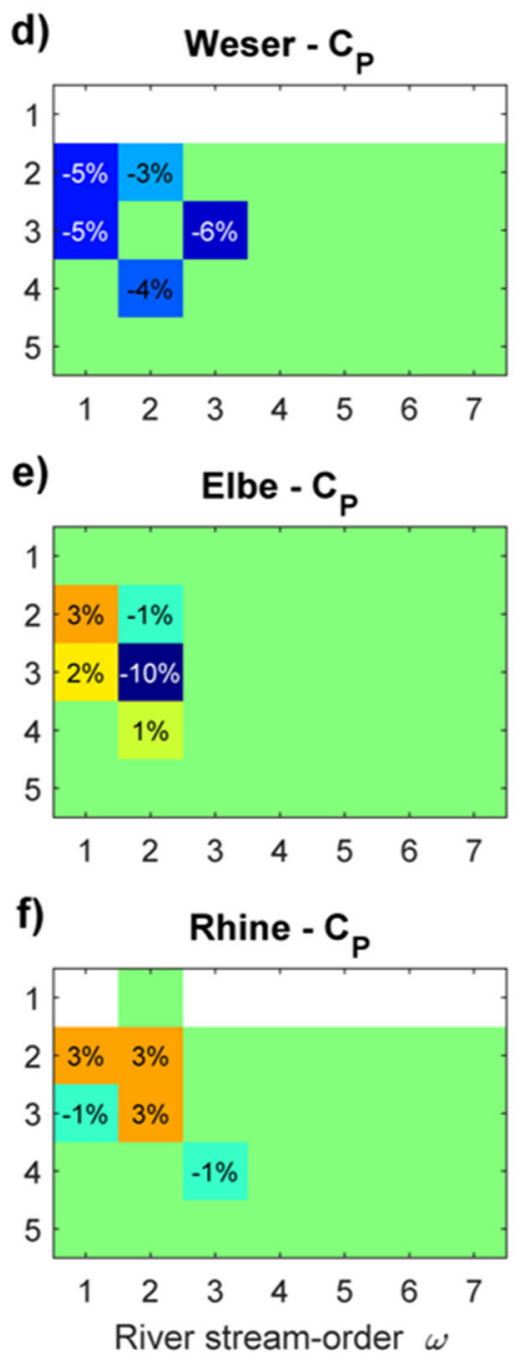

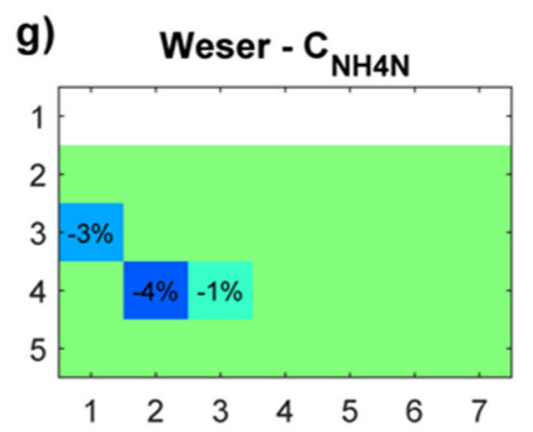

h)
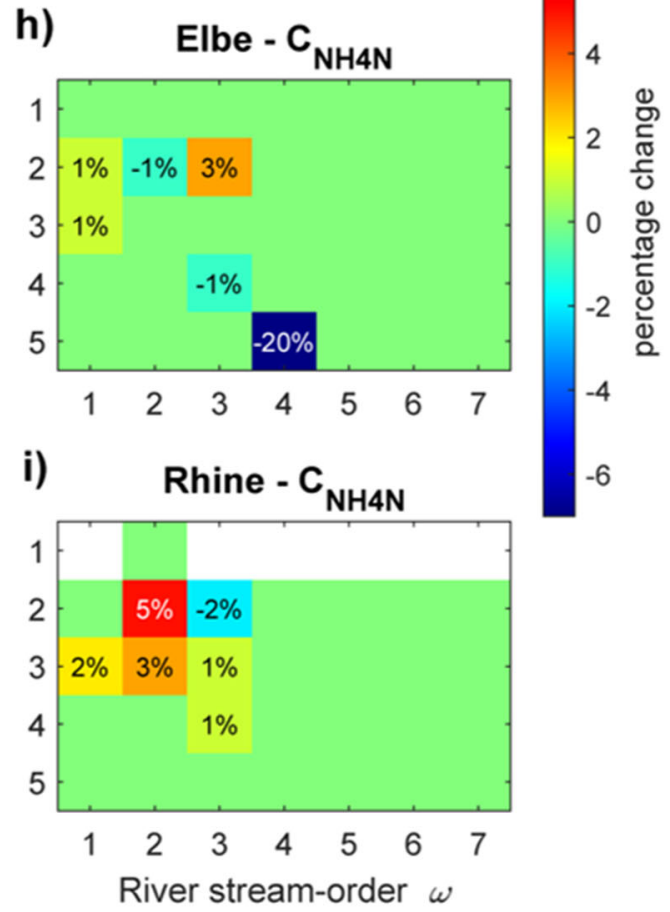

Figure 3. Changed $\%$ of WWTP-CER from historical to the far future scenario at the local-scale based on WWTP* $*_{50}$ threshold. Each $\%$ in difference was distributed by stream-order $\omega$ in the abscissa and by WWTP-size $\mathrm{k}$ in the ordinate for three environmental indicators (by columns) in each river basin (by rows). Presented results were based on the WWTP-effluents estimated with $\gamma=90$ th and $\varepsilon=10$ th percentiles. 


\subsection{Multi-criteria risk assessment at local-scale}

Multi-criteria assessment of WWTP-CER was conducted for the same results presented in Figure 2, by simultaneously evaluating the risk-status for all three indicators and thus categorizing four risk-types from none to all indicators (Figs. 4a, c, e). Around half of total WWTPs for each catchment (47 56\%) were estimated as not causing risks for all three indicators (i.e., WWTP-notCER). In contrast, the WWTP-CER for all indicators accounted for $\sim 23 \%$ for the Weser, and $\sim 30 \%$ for both the Elbe and the Rhine. The estimated fraction for each of the three catchments was slightly lower than that of WWTP-CER solely for the TP indicator, indicating that the risk-status for the TP mostly coincided with that for the other two indicators. The finding suggests that prioritizing technological advancement for the WWTP-CER for the TP can yield remarkable reductions of the most severe risk from all three indicators as well as to resolve the water quality problem from the TP itself.

More than $90 \%$ of the WWTP-CER for all three indicators were clustered in the lowerorder streams $(\omega<3)$ for the three catchments (Figs. $\mathbf{4 b}, \mathbf{d}, \mathbf{f})$. Distributions of the WWTP-CER for one or two indicators were also strongly skewed towards the smaller streams. On the other hand, less than $20 \%$ of the WWTPs without any risks were located in the streams of lower-orders. The findings evidently showed that smaller streams are highly endangered by the WWTP-effluents for what concerns both quantity and quality indicators at local-scale.

The projected vulnerability of lower-order streams to WWTPs-effluents under climate change obviously underpins the urgent needs for planning and implementing adaptation measures to protect smaller streams, which are biogeochemically more reactive and ecologically more diverse (Wohl, 2017; Richardson, 2019). A typical transport route of urban wastewater and therein contaminants from sources, modulator, and to receiver (i.e., multiple households, a WWTP, and a river reach respectively) suggests the three main stages to which distinct adaptation measures shall be applied. Firstly, controlling domestic sources of nutrients can contribute to decline in total input loads incoming to a WWTP (people-lifestyle adaptation). Main sources of the nutrients (N and P) in daily life are attributed to foods and cleansing products. Knowing the required essential intake of $\mathrm{N}$ and $\mathrm{P}$ ingredients for human nutrition balance, the associated adaptation strategy needs to be targeted for advising environmentally sustainable food consumption patterns such as lower 
frequency of taking high protein nutritional supplements (Wang et al., 2019). Innovative developments and replacement of cleansing and consumer products currently containing phosphate with functionally equivalent but environmentally less polluted chemical compounds are required (Chong et al., 2019).

Secondly, upgrading treatment technology to remove more nutrients in the WWTP can reduce nutrient loads outgoing at the end-of-pipe (engineered-system adaptation). Smaller WWTP-CER can be improved by installing the advanced tertiary treatment technology (Rahman et al., 2016; Mažeikienė, 2019). On the other hand, remarkable breakthrough in developing new treatment technology is highly vital for resolving the expected risks of larger WWTPs, since they already deploy the most advanced technology at present standards (Stoddard et al., 2003; Carvalho et al., 2019).

Last adaptation measures can be formulated by redirecting travel paths of WWTPdischarges before reaching its receiving river stream (effluent-pathway adaptation). For instance, building constructed wetlands in combination with the engineered treatment systems can delay the arrival time and amount of nutrients loads discharged from WWTPs to receiving river bodies (Wu et al., 2015; Bolton et al., 2019). Particularly for larger WWTP-CER discharging to a smaller stream, dispersing a proportion of its effluents into near larger streams with greater dilution capacity can distribute the associated stresses induced by urban wastewater that are currently entirely bore by smaller stream reaches. Accordingly, smaller streams can be less compromised by larger WWTPs-effluents at the local-scale.

In addition to the aforementioned measures for adaptation in socio-economic and technologic manners, adaptive adjustments need to be conducted regarding environmental policies and regulations of WWTPs-effluents. At present, EU-scale regulations of nutrients concentrations at the end-of-pipe are defined by technology-based approaches, and thus applied only for two largest size-classes of WWTPs (EEC, 1991). Over the three catchments, 1,570 WWTPs ( 49 \% of the total $\sim 3,200$ ) were legitimate targets for applying the regulations. In case of total P indicator, $\sim 91 \%$ of total WWTPs under the regulations satisfied the requirements for WWTP-discharged concentration to be lower than the defined thresholds (i.e., 2 and $1 \mathrm{mgP} / \mathrm{L}$ for size-classes 4 and 5, respectively). Nevertheless, the remarkably high compliance of larger WWTPs with the 
requirements did not completely ensure water quality protection of their receiving river reaches, as shown by the evaluated $\sim 30 \%$ of the larger WWTPs at local-scale risk. The finding highlighted the need for incorporating hydrological conditions and water-quality-based effluent standards into the original regulations purely based on technology, as actively acknowledged since few decades (Ragas et al., 2005; Çelebi et al., 2021; Gursoy-Haksevenler et al., 2021). The proposed $k-\omega$ framework stands as a crucial solution to conceptualize and systematize the combined technologyand water-quality-based discharge limits at the scale of entire river networks.
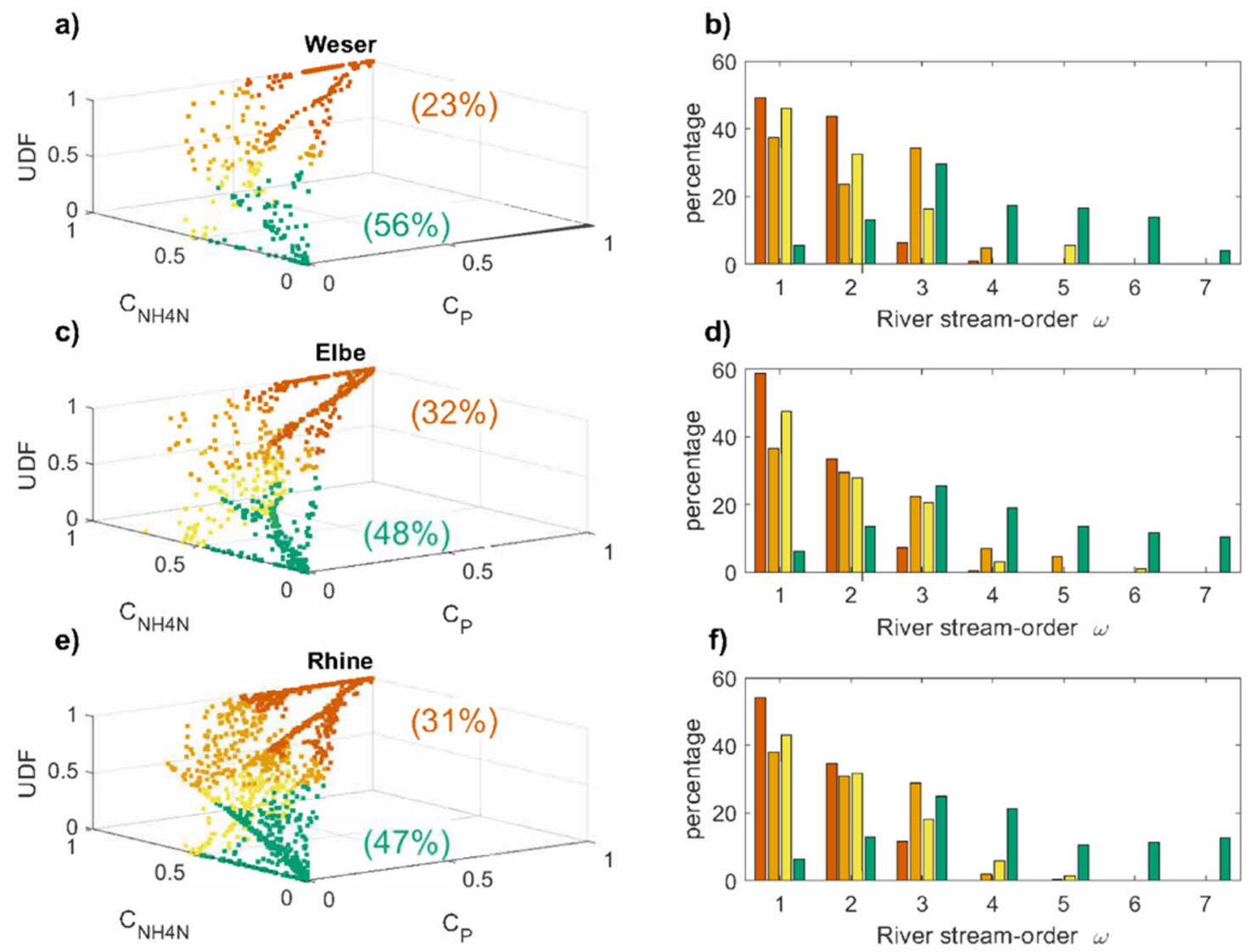

- WWTP-CER for three indicators

- WWTP-CER for two indicators

WWTP-CER for one indicator $\bullet$ WWTP-not-CER

Figure 4. Multi-criteria assessment to categorize WWTPs by the level of risk-types at the localscale under the far future scenario. Note that the assessment used the same results presented in Figure 2, for (a) the Weser, (c) the Elbe, and (e) the Rhine. Four levels of risk-types are defined as the number of indicators causing under ecological risks. Zero in green to all three indicators in red. Numbers in parentheses indicate the fraction of WWTPs with the two extreme levels out of total WWTPs ( 480 in Weser, 900 in Elbe, and 1820 in Rhine). Distributions in \% for each level of risk-type over stream-orders $\omega$ are given for (b) the Weser, (d) the Elbe, and (f) the Rhine. 


\subsection{Basin-scale risk assessment}

We evaluated the cumulative effects of water flux in the WWTPs-effluents by calculating the basin-scale UDF under far future scenario (Eq. 3) at the points of each WWTP location along converging flow paths. The basin-scale risk for UDF was assessed under the threshold of WWTP* ${ }_{50}$. The assessment criteria based on the explicit WWTP-locations and the WWTP* ${ }_{50}$ threshold under the far future scenario aimed to be consistent with the perspectives used for the local-scale risk assessment. Note that we described the WWTP location facing risk for UDF at the basin-scale by using the term of 'WWTP-LFR' instead of WWTP-CER, to differentiate the basinscale results from the local-scale ones related to the direct effluent of a given WWTP.

The cumulative effects for UDF contributed to the increase of WWTP-LFR for all three catchments (Figs. 5a-c). The incremental fraction was estimated as $\sim 34 \%$ for the Weser, and $\sim 40 \%$ for the Elbe and the Rhine, out of all WWTP-locations for each catchment. It was attributed to cases that the UDF risk-status was shifted from not-causing-risk under local-scale to causing-risk under basin-scale, which denoted as hereafter ' $\Delta$ RiskBs'. The finding suggests that the locallysufficient dilution capacity of river discharge at a given location can be jeopardized by the cumulated magnitude of WWTPs-effluents along converging flow paths.

The WWTP-LFR with $\triangle$ RiskBs were not evenly distributed across stream-orders $\omega$ and sizeclasses $k$ (Figs. 5d-f). Rather, they were strongly clustered in $\omega>3$, accounting for $70 \sim 80 \%$ of total cases for each catchment. The finding reasonably mirrored that the large fraction of WWTPs in $\omega<4$ was already evaluated as WWTP-CER under local-scale. Within higher-order streams ( $\omega$ $>3$ ), the greatest fraction of the WWTP-LFR with $\Delta$ RiskBs was found in $k=4$ for all three catchments, because of the largest fraction of WWTPs with $k=4$ among all size-classes. However, for a given $k$ across $\omega=4 \sim 7$, the fraction of the WWTP-LFR with $\Delta$ RiskBs to the total number of WWTP-LFR was the largest in $k=5$ (90 95\%), followed by $k=4(78 \sim 90 \%)$ for all three catchments. The findings can help understanding how water quality pollution induced by lessreactive pollutants in WWTPs-emissions would be propagated downstream as they flow along stream networks (Schmidt et al., 2020). Furthermore, the core principle of basin-scale assessment conducted here can be transferred to discern cascading degradation towards downstream for river water quality induced by WWTP-discharged pollutants, particularly those which are not affected 
by in-stream processes (e.g., retention or release). To the best of our knowledge, the accumulated effect of urban wastewater pressure from WWTPs has been explored in spatially implicit approach as a simple sum of water flux over large catchments (Keller et al., 2014; Karakurt et al., 2019; Abily et al., 2021). Conversely, the application of the $k$ - $\omega$ framework allows for spatially explicit evaluation of cumulative effluents for multiple WWTPs within a catchment.

a)

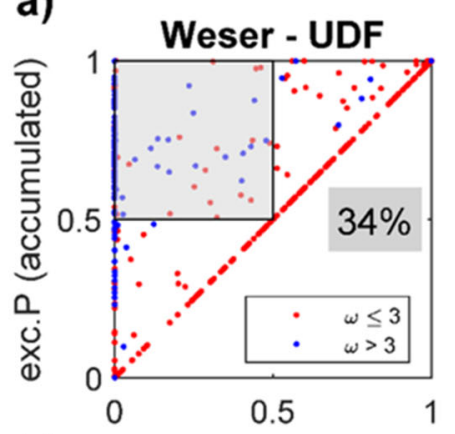

b)

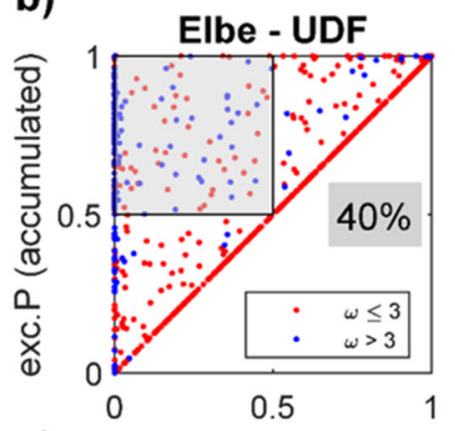

c)

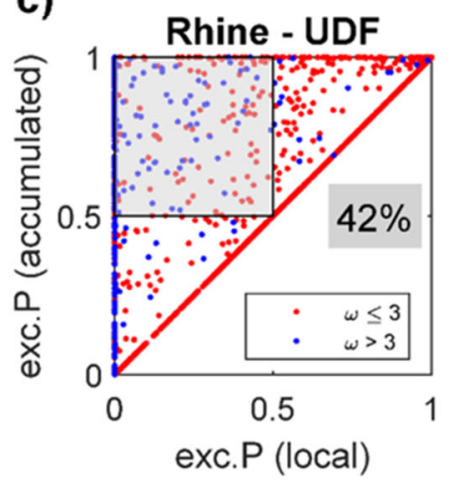

d)

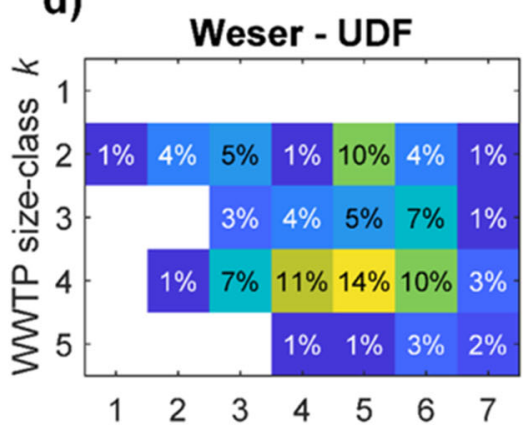

e)

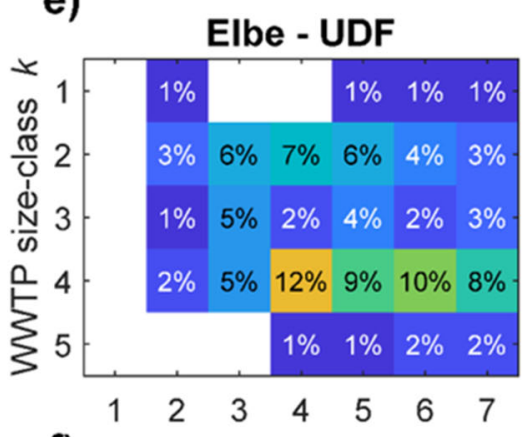

f)

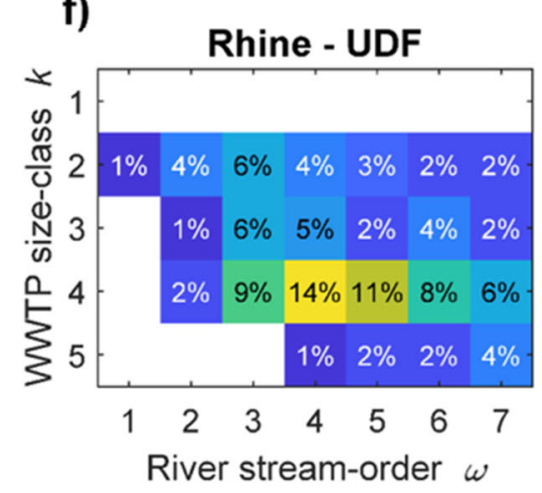

Figure 5. Assessment of the WWTP location facing risk for UDF at the basin-scale, with accumulated aspect under the far future scenario, WWTP-LFR. (a-c) Comparison of the exceedance probability having UDF* for individual WWTPs, between the local-scale and the basin-scale, for the three river basins. Gray regions represent the case of not-causing-risk under the local-scale but causing-risk under the basin scale (i.e., defined as $\Delta$ RiskBs) by applying the WWTP* ${ }_{50}$ threshold. Fraction of WWTPs within the gray regions is given in each inserted number. (d-f) Distribution of the WWTPs within each gray region by stream-order $\omega$ in the abscissa and by WWTP-size $\mathrm{k}$ in the ordinate, for the three river basins. 


\subsection{Limitations of this study}

We acknowledge inherent uncertainties in our assumptions of spatially homogeneous and temporally constant per-capita daily production of water and nutrients for people residing in the three study catchments. On the other hand, we explicitly accounted for the spatial and temporal dynamics of hydrological flow regimes in the receiving rivers for both the historical and far future periods. This was intended in the scope of this study, which primarily aimed to develop a systematic, generic, and transferable framework for ecological risk assessments of WWTPseffluents in any river basin for any time period under expected global changes. Thus, it was inevitable to reduce the spatio-temporal complexity in the emission to receiving water perspective, in turn focusing on changing river hydrological conditions which influence multiple sectors including drinking water availability under global changes. Simultaneously, we noted that residents in the selected three catchments shared and will display strong similarities in life-styles and behavioral characters such as food and water consumptions, with the situation on other European countries (Wang et al., 2019; EurEup, 2020). This suggests that main results of this study (e.g., at local-scale smaller streams are expected to be more compromised by effluents of greater WWTPs) will be confirmed, while the fraction of WWTP-CER only will change, as futureprojected values for the resources consumption per person will be explicitly reflected in the estimates. Note that uncertainty analyses for the three catchments are outside the scope of this study, rather anticipated in following research.

Another source of uncertainty for our results might be simulation data obtained from only one hydrological model and referring to climate condition simulated by a single GCM considering only the most extreme scenario regarding RCP and warming level. Uncertainty in each simulation result from different combinations between climate change and hydrological models exists. Hence, additional processes that quantify the uncertainty within a model or across different models (e.g., ensemble analyses) are importantly conducted in the fields of modelling future-projected climatic or hydrological properties. However, it should be noted that our scope is not to provide the most accurate assessment of the ecological risk of WWTPs-effluents under climate change, but to underpin the proposed risk assessment framework based on a plausible and reliable scenario for projected climate change. For a given set of climate-hydrological models, additional intermediate RCP and lower warming level conditions will lead to overall less fraction of WWTP-CER over a 
river network, but not necessarily proportional across stream-orders due to nonlinearity in the coupled meteorological-hydrological processes. Decisions on the types of climate and hydrological models and the conditions of RCP and warming level are not crucial in the scope of this study, which aims at presenting the main features and an application of the risk assessment framework.

\subsection{Future outlook}

The systematic and generic risk assessment framework presented here can be flexibly transferred to larger spatial extents, more elaborated temporal dynamics and other proxies regarding ecological or human health related impacts. Continental or global-scale extensions of the framework will allow for evaluating the environmental policy on discharges from WWTPs or for assessing progress to meet legally-binding international commitments to water quality protection in a consistent way. For example, all EU states are required to achieve the EU WFD's goal to make all river water bodies be at least with good-ecological status by 2027 . To mitigate adverse impacts of WWTPs-effluents on this goal, the EU UWWTD has been implemented commonly across the EU to regulate WWTPs-effluents categorized by the WWTP-sizes related to treatment levels. In fact, the European countries spanning the study catchments are categorized in the uppermost class regarding the fraction of people connected to the most advanced tertiary level treatment, which is 15 30\% higher than the EU-average as of 2017 (EEA, 2020b). The EU UWWTD stipulates the most stringent regulations for WWTPs deploying tertiary level in terms of nutrient concentrations discharged from WWTPs. Nonetheless, as this study showed, even the most stringent regulations on WWTPs-effluents can pose ecological risks especially to smaller streams. Thus, our findings underpin the necessity of additional systematic categories to elaborate the regulations, such as by following the river network hierarchy. Adverse effects highlighted here may be more prominent in other European catchments spanning countries with lower connection of people to tertiary-level treatment. Further analyses at EU-scale are required to support or contradict this hypothesis; such efforts are currently underway.

In addition, global-scale extension is necessary and promising. Although global south have released wastewaters to the environment without appropriate treatment, the majority of river 
streams in the region are still in good condition (UNEP, 2016). However, facing a worldwide growing population, the number of births in the global south will continue to increase until 2050, and thereby waste production and economic activities will be highly accelerated (UN, 2019). If the current options of wastewater management remain the same over the upcoming decades, further pollutions in rivers are a matter of time and already-polluted streams lose an opportunity for restoration. These outcomes are significantly likely to limit the achievement of SDG 6 ultimately aiming to universal access to clean water. Upscaling the presented framework globally can facilitate to assess progress towards the accomplishment of SDG 6, by integrating open-source global-scale data for river networks, WWTPs (Lehner et al., 2008; Jones et al., 2021) as well as projected data of population, water and food consumption patterns, and hydrological modelling (UN, 2019; Wang et al., 2019; Krysanova et al., 2020).

This study laid the foundation towards a holistic decision support system by providing a framework to identify hotspots of impact by WWTPs-effluents and the discharges of treated wastewater into streams and rivers. To achieve such a holistic assessment, the following steps are essential: 1) multiple scenarios analyses to guide for reducing WWTP-CER, 2) cost effectiveness analysis for each scenario to inform decision options. Note that a wide range of measures exist in formulating alternative scenarios, and are inevitably dependent on regional conditions regarding technology, economy, policy, and residents' life-styles (UNEP, 2016). Exemplary technical measures are to upgrade treatment technology, to change the number of people served, to redirect sewage to already existing or newly built WWTPs with greater dilution capacity, and to deploy nature based solutions such as constructed wetlands to delay arriving-time of WWTPs-effluents to river networks. A typical but complex, non-technical societal measures can be to legislate household-sources control policy by regulating per-capita consumption of water, harmful substances, and/or supplementary protein foods. Next studies on scenario-based analyses are expected to demonstrate the suitability and effectiveness of individual or coupled adaptation measures to reduce the adverse effects of WWTPs-effluents on smaller streams under climate change. Such studies can contribute to secure water quality and the integrity of aquatic ecosystems under global changes. 


\section{Conclusions}

This study aimed to develop a new, systematic, and transferable framework providing firstorder diagnosis for ecological risks caused by individual WWTPs-effluents on receiving streams and rivers at catchment-scale under climate change. The framework consisted of the combination of two fundamental characteristics for the number of people served by WWTPs (WWTP-size $k$ ) and for river network hierarchy (stream-order $\omega$ ), named as the $k-\omega$ framework. Three environmental proxy indicators of concern were analyzed: The local-scale concentrations of dominant wastewater components (total phosphorus and ammonium-nitrogen; P and NH4N) and the local fraction of treated wastewater pressures related to natural flows (UDF). Our novel approach for risk analyses synthesizes multiple data on river network, WWTP-properties, modelled streamflow under a projected climate scenario, and socio-economic characteristics. Focusing on the scope of this study, we only referred to the most extreme warming scenario in the far future and its corresponding simulated streamflow data from a mesoscale hydrological model. The historical period was compared as a reference condition.

We selected three large Central European catchments as study areas (Rhine, Elbe, and Weser). The Rhine and Elbe possess noticeably contrasting characters in terms of climatic, hydrological, river ecosystem responses, whereas surprisingly common behaviors exist in the coupled human-WWTP systems and daily lifestyles. For all indicators, lower-order streams in the three catchments were more threatened from WWTPs-effluents, especially by greater sizes. This finding suggests the urgent needs for organizing next actions to protect smaller streams which play crucial roles in providing sources of water flows, and in keeping aquatic ecosystems integrity. The lowest fraction of WWTP-CER for all indicators in the Weser underpinned that less centralized distribution of people and wastewater infrastructures might yield less ecological risks in receiving rivers. Among the three considered indicators, the risk for NH4N was the highest due to higher contributions of smaller-sized WWTPs in all catchments. This result urges to develop legislative regulations for effluents from smaller-WWTPs, which are not currently defined. Changing hydrological conditions from historical to future climates resulted in catchment- and indicatorspecific differences in the fraction of WWTP-CER. Nonetheless, most of the differences were identified in smaller streams receiving effluents of intermediate-sized WWTPs. 
In addition to the perspectives for individual indicators, multi-criteria risk assessment approaches such as the one presented here can be used to design, plan, and implement tailored solutions to reduce hot-spots of environmental pressures induced by WWTPs-effluents. The holistic decision support system can be applicable to any geophysical regions spanning any climate zones. A strategic prioritization of technical adaptations for WWTP-CER can be facilitated by categorizing the type of ecological risks. In this context, the proposed $k$ - $\omega$ framework based on a data-model synthesis has significant potentials by serving as a tool to screen effects of new policy and/or evaluate currently implemented policies. The $k-\omega$ framework can also be applied for newly emerging contaminants in WWTPs-effluents, and thus help to advance the science base for setting environmental standards. Furthermore, the $k$ - $\omega$ framework allows for scenario-based analyses by explicitly taking into consideration growing population and changing lifestyles over the upcoming decades, and thereby facilitates assessment of progress towards continental- and global-scale goals for securing water resources and aquatic ecosystems including their biodiversity.

\section{Acknowledgments}

This study was funded by the Helmholtz Climate Initiative Project (www.helmholtz-klima.de) being conducted across the Helmholtz Association. We thank Gert Schwentner from the German Association for Water, Wastewater and Waste (DWA) for providing data on treatment efficiency of German WWTPs. We also acknowledge datasets of the mHM simulations from EDgE project (http://edge.climate.copernicus.eu/; Projection data at DOI: 10.24381/cds.ccf781a2) of the Copernicus Climate Change Service. Dataset of the EU Hydro and the EEA WWTPs are publically available. The daily streamflow data simulated using the $\mathrm{mHM}$ is available through Marx et al. (2018), Thober et al. (2018), and Samaniego et al. (2019). 


\section{References}

Abily, M., Acuña, V., Gernjak, W., Rodríguez-Roda, I., Poch, M., \& Corominas, L. (2021). Climate change impact on EU rivers' dilution capacity and ecological status. Water Res., 199, 117166. doi:10.1016/j.watres.2021.117166.

Ansorge, L., Stejskalová, L., \& Dlabal, J. (2020). Effect of WWTP size on grey water footprint-Czech Republic case study. Environ. Res. Lett., 15(10), 104020. doi:10.1088/1748-9326/aba6ae.

Arden, S., \& Jawitz, J. W. (2019). The evolution of urban water systems: societal needs, institutional complexities, and resource costs. Urban Water J., 16(2), 92-102. doi:10.1080/1573062X.2019.1634109.

ATV-DVWK. (2003). Arbeitsblatt A-198. Vereinheitlichung und Herlegung von Bemessungswerten für Abwasseranlagen. (Translation: Standardization and Derivation of Design for Sewer Systems).

Büttner, O., Jawitz, J. W., \& Borchardt, D. (2020). Ecological status of river networks: stream orderdependent impacts of agricultural and urban pressures across ecoregions. Environ. Res. Lett., 15(10), 1040b1043. doi:10.1088/1748-9326/abb62e.

BBC. (2018, July 02). Heatwave leads to increased demand for water. UK Heatwaves. from https://www.bbc.com/news/uk-northern-ireland-44676684

BMUB/UBA. (2014). Water Resource Management in Germany - Part 2: Water quality. The Environment, Nature Conservation, Building and Nuclear Safety (BMUB) and the German Federal Environmental Agency (UBA). Retrieved from https://www.umweltbundesamt.de/publikationen/waterresource-management-in-germany-part-2.

Bolton, L., Joseph, S., Greenway, M., Donne, S., Munroe, P., \& Marjo, C. E. (2019). Phosphorus adsorption onto an enriched biochar substrate in constructed wetlands treating wastewater. Ecol. Eng. $X, 1$, 100005. doi:10.1016/j.ecoena.2019.100005.

Carvalho, L., Mackay, E. B., Cardoso, A. C., Baattrup-Pedersen, A., Birk, S., Blackstock, K. L., ... Solheim, A. L. (2019). Protecting and restoring Europe's waters: An analysis of the future development needs of the Water Framework Directive. Sci. Total Environ., 658, 1228-1238. doi:10.1016/j.scitotenv.2018.12.255.

Çelebi, S., Yetis, U., \& Ünlü, K. (2021). A practical approach for the determination of environmental quality standards-based discharge limits: the case of Tersakan sub-basin of Yeşilırmak River in Turkey. Environ. Sci. Pollut. R., 28(29), 38730-38748. doi:10.1007/s11356-021-13350-6.

Chong, J., Dominish, E., Tjandraatmadja, G., Prentice, E., Retamal, M., \& Mitrovic, S. (2019). Ecosystem impacts of phosphorus and surfactants in consumer products. Institute for Sustainable Futures, University of Technology Sydney. 
DWA. (2019). 32. Leistungsnachweis kommunaler Kläranlagen - Klärschlammanfall. [32. Proof of achievement : Municipal sewage treatment plants]. German Association for Water Management, Wastewater and Waste.

EC. (1991). Council Directive 91/271/EEC of 21 May 1991 concerning urban waste-water treatment. Official Journal of the European Union

EC, \& EEA. (2020, March 04). Water uses to cope with heat waves in cities. Climate-ADAPT. from https://climate-adapt.eea.europa.eu/metadata/adaptation-options/water-uses-to-cope-withheat-waves-in-cities

EEA. (2015). Freshwater quality. European Environment Agency (EEA) Report.

EEA. (2019). UWWTD database version 5. from https://www.eea.europa.eu/data-andmaps/data/waterbase-uwwtd-urban-waste-water-treatment-directive-6

EEA. (2020a). EU-Hydro - River Network Database, Version 1.0. from https://www.eea.europa.eu/dataand-maps/data/external/eu-hydro-2013-river-network.0

EEA (2020b). Urban Waste Water Treatment in Europe. European Environment Agency, Copenhagen, Denmark: $\quad$ https://www.eea.europa.eu/data-and-maps/indicators/urban-waste-watertreatment/urban-waste-water-treatment-assessment-5.

EEC. (1991). Council Directive of 21 May 1991 Concerning Urban Waste Water Treatment (91/271/EEC). Official Journal of the European Communities. Retrieved from http://ec.europa.eu/environment/water/water-urbanwaste/index en.html.

EurEup. (2020). The governance of water services in Europe. (978-2-9602226-2-3).

European Commission. (2000). Directive 2000/60/EC of the European Parliament and of the Council of 23 October 2000 Establishing a Framework for Community Action in the Field of Water Policy. Official Journal of the European Communities. Retrieved from http://ec.europa.eu/environment/water/water-framework/index en.html.

Freni, G., Mannina, G., \& Viviani, G. (2010). Emission standards versus immission standards for assessing the impact of urban drainage on ephemeral receiving water bodies. Water Sci. Technol., 61(6), 1617-1629. doi:10.2166/wst.2010.887.

Gücker, B., Brauns, M., \& Pusch, M. T. (2006). Effects of wastewater treatment plant discharge on ecosystem structure and function of lowland streams. Journal of the North American Benthological Society, 25(2), 313-329. doi:10.1899/0887-3593(2006)25[313:eowtpd]2.0.co;2.

Glassman, M. (2018, July 11). Residents asked to space out water usage during heat wave. Allen Media Broadcasting. from https://www.kezi.com/content/news/SUB-is-asking-people-to-space-outwater-usuage-ahead-of-heatwave--487955431

Gursoy-Haksevenler, B. H., Atasoy-Aytis, E., Dilaver, M., Yalcinkaya, S., Findik-Cinar, N., Kucuk, E., ... Yetis, U. (2021). A strategy for the implementation of water-quality-based discharge limits for the 
regulation of hazardous substances. Environ. Sci. Pollut. R., 28(19), 24706-24720. doi:10.1007/s11356-020-10220-5.

Hardenbicker, P., Rolinski, S., Weitere, M., \& Fischer, H. B. (2014). Contrasting long-term trends and shifts in phytoplankton dynamics in two large rivers. International Review of Hydrobiology, 99(4), 287299. doi:10.1002/iroh.201301680.

Hardenbicker, P., Weitere, M., Ritz, S., Schöll, F., \& Fischer, H. (2016). Longitudinal plankton dynamics in the Rivers Rhine and Elbe. River Research and Applications, 32(6), 1264-1278. doi:10.1002/rra.2977.

Hari, V., Rakovec, O., Markonis, Y., Hanel, M., \& Kumar, R. (2020). Increased future occurrences of the exceptional 2018-2019 Central European drought under global warming. Scientific Reports, 10(1), 12207. doi:10.1038/s41598-020-68872-9.

HDR. (2002). Handbook of Public Water Systems (2nd ed.): John Wiley \& Sons.

Heidecke, C. , Hirt, U., Kreins, P., Kuhr, P., Kunkel, R., Mahnkopf, J., . . Wendland, F. (2015). Endbericht zum Forschungsprojekt "Entwicklung eines Instrumentes für ein flussgebietsweites Nährstoffmanagement in der Flussgebietseinheit Weser". Thünen Report 21.

Hoffmann, T. O., Baulig, Y., Fischer, H., \& Blöthe, J. (2020). Scale breaks of suspended sediment rating in large rivers in Germany induced by organic matter. Earth Surface Dynamics, 8(3), 661-678. doi:10.5194/esurf-8-661-2020.

Horton, Robert E. (1945). Erosional development of streams and their drainage basins; hydrophysical approach to quantitative morphology. Geological society of America bulletin, 56(3), 275-370

Hulley, G. C., Dousset, B., \& Kahn, B. H. (2020). Rising trends in heatwave metrics across southern California. Earth's Future, 8(7), e2020EF001480. doi:10.1029/2020EF001480.

Ionita, M., \& Nagavciuc, V. (2020). Forecasting low flow conditions months in advance through teleconnection patterns, with a special focus on summer 2018. Scientific Reports, 10(1), 13258. doi:10.1038/s41598-020-70060-8.

Jones, E. R., van Vliet, M. T. H., Qadir, M., \& Bierkens, M. F. P. (2021). Country-level and gridded estimates of wastewater production, collection, treatment and reuse. Earth System Science Data, 13(2), 237-254. doi:10.5194/essd-13-237-2021.

Kamjunke, N., Rode, M., Baborowski, M., Kunz, J. V., Zehner, J., Borchardt, D., \& Weitere, M. (2021). High irradiation and low discharge promote the dominant role of phytoplankton in riverine nutrient dynamics. Limnol. Oceanogr., 66(7), 2648-2660. doi:10.1002/Ino.11778.

Karakurt, S., Schmid, L., Hübner, U., \& Drewes, J. E. (2019). Dynamics of wastewater effluent contributions in streams and impacts on drinking water supply via riverbank filtration in Germany - A national reconnaissance. Environ. Sci. Technol., 53(11), 6154-6161. doi:10.1021/acs.est.8b07216. 
Keller, V. D. J., Williams, R. J., Lofthouse, C., \& Johnson, A. C. (2014). Worldwide estimation of river concentrations of any chemical originating from sewage-treatment plants using dilution factors. Environ. Toxicol. Chem., 33(2), 447-452. doi:10.1002/etc.2441.

Krysanova, V., Zaherpour, J., Didovets, I., Gosling, S. N., Gerten, D., Hanasaki, N., ... Wada, Y. (2020). How evaluation of global hydrological models can help to improve credibility of river discharge projections under climate change. Climatic Change, 163(3), 1353-1377. doi:10.1007/s10584-02002840-0.

Kumar, R., Samaniego, L., \& Attinger, S. (2013). Implications of distributed hydrologic model parameterization on water fluxes at multiple scales and locations. Water Resour. Res., 49(1), 360379. doi:10.1029/2012WR012195.

Labbe, S. (2021, June 30). Heat wave pushes Metro Vancouver to 'unprecedented' early season water use. Glacier Media Group. from https://www.vancouverisawesome.com/local-news/heat-wavepushes-metro-vancouver-to-unprecedented-early-season-water-use-3921388

Lehner, B., Verdin, K., \& Jarvis, A. (2008). New global hydrography derived from spaceborne elevation data. Eos, Transactions American Geophysical Union, 89(10), 93-94. doi:10.1029/2008EO100001.

Li, R., Hua, P., Zhang, J., \& Krebs, P. (2020). Effect of anthropogenic activities on the occurrence of polycyclic aromatic hydrocarbons in aquatic suspended particulate matter: Evidence from Rhine and Elbe Rivers. Water Res., 179, 115901. doi:10.1016/j.watres.2020.115901.

Lomax, C. (2021, July 21). Water consumption soars during heatwave. Ilkley Gazette. from https://www.ilkleygazette.co.uk/news/19457870.water-consumption-soars-heatwave

Marx, A., Kumar, R., Thober, S., Rakovec, O., Wanders, N., Zink, M., . . Samaniego, L. (2018). Climate change alters low flows in Europe under global warming of $1.5,2$, and $3{ }^{\circ} \mathrm{C}$. Hydrol. Earth Syst. Sci., 22(2), 1017-1032. doi:10.5194/hess-22-1017-2018.

Mažeikienè, A. (2019). Improving small-scale wastewater treatment plant performance by using a filtering tertiary treatment unit. J. Environ. Manage., 232, 336-341. doi:10.1016/j.jenvman.2018.11.076.

Naik, K. S., \& Stenstrom, M. K. (2012). Evidence of the influence of wastewater treatment on improved public health. Water Sci. Technol., 66(3), 644-652. doi:10.2166/wst.2012.144.

Nivala, J., van Afferden, M., Hasselbach, R., Langergraber, G., Molle, P., Rustige, H., \& Nowak, J. (2018). The new German standard on constructed wetland systems for treatment of domestic and municipal wastewater. Water Sci. Technol., 78(11), 2414-2426. doi:10.2166/wst.2018.530.

Pearlman, J. (2018, January 08). Sydney swelters in heatwave, water usage at highest level in 15 years. Straits Times. from https://www.straitstimes.com/asia/australianz/weekend-heatwave-makessydney-the-hottest-city-on-earth

Pfeiffer, M., \& Ionita, M. (2017). Assessment of hydrologic alterations in Elbe and Rhine Rivers, Germany. Water, 9(9), 684. doi:10.3390/w9090684. 
Pusch, M. T., Behrendt, H., Gancarczyk, A., Kronvang, B., Sandin, L., Stendera, S., . . Wnuk-Gławdel, E. (2009). Chapter 14 - Rivers of the Central European Highlands and Plains. In K. Tockner, U. Uehlinger \& C. T. Robinson (Eds.), Rivers of Europe (pp. 525-576). London: Academic Press.

Ragas, A. M. J., Scheren, P. A. G. M., Konterman, H. I., Leuven, R. S. E. W., Vugteveen, P., Lubberding, H. J., . . Stortelder, P. B. M. (2005). Effluent standards for developing countries: combining the technology- and water quality-based approach. Water Sci. Technol., 52(9), 133-144. doi:10.2166/wst.2005.0304.

Rahman, S. M., Eckelman, M. J., Onnis-Hayden, A., \& Gu, A. Z. (2016). Life-cycle assessment of advanced nutrient removal technologies for wastewater treatment. Environ. Sci. Technol., 50(6), 3020-3030. doi:10.1021/acs.est.5b05070.

Rice, J., \& Westerhoff, P. (2017). High levels of endocrine pollutants in US streams during low flow due to insufficient wastewater dilution. Nat. Geosci., 10, 587. doi:10.1038/ngeo2984.

Richardson, J. S. (2019). Biological diversity in headwater streams. Water, 11(2), 366. doi:10.3390/w11020366.

Ritz, S., \& Fischer, H. (2019). A mass balance of nitrogen in a large lowland river (Elbe, Germany). Water, 11(11), 2383. doi:10.3390/w11112383.

Samaniego, L., Kumar, R., \& Attinger, S. (2010). Multiscale parameter regionalization of a grid-based hydrologic model at the mesoscale. Water Resour. Res., 46(5). doi:10.1029/2008wr007327.

Samaniego, L., Thober, S., Wanders, N., Pan, M., Rakovec, O., Sheffield, J., . . . Kumar, R. . (2019). Hydrological forecasts and projections for improved decision-making in the water sector in Europe. Bulletin of the American Meteorological Society, 100(12), 2451-2472. doi:10.1175/BAMSD-17-0274.1.

Schmidt, C., Kumar, R., Yang, S., \& Büttner, O. (2020). Microplastic particle emission from wastewater treatment plant effluents into river networks in Germany: Loads, spatial patterns of concentrations and potential toxicity. Sci. Total Environ., 737, 139544. doi:10.1016/j.scitotenv.2020.139544.

Sheldon, F., Barma, D., Baumgartner, L. J., Bond, N., Mitrovic, S. M., \& Vertessy, R. (2021). Assessment of the causes and solutions to the significant 2018-19 fish deaths in the Lower Darling River, New South Wales, Australia. Marine and Freshwater Research, -. doi:10.1071/MF21038.

Siddiqui, S., Conkle, J. L., Scarpa, J., \& Sadovski, A. (2020). An analysis of U.S. wastewater treatment plant effluent dilution ratio: Implications for water quality and aquaculture. Sci. Total Environ., 721, 137819. doi:10.1016/j.scitotenv.2020.137819.

Stoddard, A., Harcum, J. B., Simpson, J. T. , Pagenkopf, J. R., \& Bastian, R. K. (2003). Municipal Wastewater Treatment: Evaluating Improvements in National Water Quality: John Wiley \& Sons.

Stott, P. (2016). How climate change affects extreme weather events. Science, 352(6293), 1517-1518. doi:10.1126/science.aaf7271. 
Strahler, A. N. (1957). Quantitative analysis of watershed geomorphology. Eos Trans. AGU, 38(6), 913-920. doi:10.1029/TR038i006p00913.

Thober, S., Kumar, R., Wanders, N., Marx, A., Pan, M., Rakovec, O., . . Zink, M. (2018). Multi-model ensemble projections of European river floods and high flows at 1.5, 2, and 3 degrees global warming. Environ. Res. Lett., 13(1), 014003. doi:10.1088/1748-9326/aa9e35.

Uehlinger, U., Arndt, H., Wantzen, K. M., \& Leuven, R. S. E. W. (2009). Chapter 6 - The Rhine River Basin. In K. Tockner, U. Uehlinger \& C. T. Robinson (Eds.), Rivers of Europe (pp. 199-245). London: Academic Press.

UN. (2015). Transforming our World: The 2030 Agenda for Sustainable Development (A/RES/70/1). United Nations. Retrieved from https://sustainabledevelopment.un.org/post2015/transformingourworld/publication.

UN. (2016). World Cities Report 2016: Urbanization and Development - Emerging Futures. United Nations Human Settlements Programme (UN-Habitat).

UN. (2019). World Population Prospects 2019 (ST/ESA/SER.A/423). United Nations Department of Economic and Social Affairs, Population Division.

UNEP. (2016). A Snapshot of the World's Water Quality: Towards a Global Assessment. (DEW/1975/NA). Nairobi, Kenya: United Nations Environment Programme.

USEPA. (1972). Federal Water Pollution Control Act (Clean Water Act). 33 U.S.C §§ 1251 et seq.

USEPA. (2015, January). Incident Action Checklist - Extreme Heat. Office of Water. from https://www.epa.gov/system/files/documents/2021-10/incident-action-checklistextremeheat 508c-final.pdf

Viessman, W., Hammer, M. J., Perez, E. M., \& Chadik, P. A. (2009). Water supply and pollution control (8th ed.): Pearson.

Wang, X., Daigger, G., de Vries, W., Kroeze, C., Yang, M., Ren, N.-Q., . . Butler, D. (2019). Impact hotspots of reduced nutrient discharge shift across the globe with population and dietary changes. Nature Communications, 10(1), 2627. doi:10.1038/s41467-019-10445-0.

Weitere, Markus, Altenburger, R., Anlanger, C., Baborowski, M., Bärlund, I., Beckers, L.-M., ... Brauns, M. (2021). Disentangling multiple chemical and non-chemical stressors in a lotic ecosystem using a longitudinal approach. Sci. Total Environ., 769, 144324. doi:10.1016/j.scitotenv.2020.144324.

Wells, R. (2014, January 29). Heatwave sparks record-breaking water use in Melbourne households. Sydney Morning Herald. from https://www.smh.com.au/environment/weather/heatwavesparks-recordbreaking-water-use-in-melbourne-households-20140128-31l1p

Westphal, K., Graeber, D., Musolff, A., Fang, Y., Jawitz, J. W., \& Borchardt, D. (2019). Multi-decadal trajectories of phosphorus loading, export, and instream retention along a catchment gradient. Sci. Total Environ., 667, 769-779. doi:10.1016/j.scitotenv.2019.02.428. 
Wohl, E. (2017). The significance of small streams. Frontiers of Earth Science, 11(3), 447-456. doi:10.1007/s11707-017-0647-y.

Wolfe, M., Kaur, M., Yates, T., Woodin, M., \& Lantagne, D. (2018). A systematic review and meta-analysis of the association between water, sanitation, and hygiene exposures and cholera in case-control studie. The American Journal of Tropical Medicine and Hygiene, 99(2), 534-545. doi:10.4269/ajtmh.17-0897.

Wu, H., Zhang, J., Ngo, H. H., Guo, W., Hu, Z., Liang, S., . . Liu, H. (2015). A review on the sustainability of constructed wetlands for wastewater treatment: Design and operation. Bioresource Technology, 175, 594-601. doi:10.1016/j.biortech.2014.10.068.

WWAP. (2017). The United Nations World Water Development Report 2017: Wastewater, The Untapped Resource. United Nations World Water Assessment Programme: Paris, UNESCO.

Yang, S., Büttner, O., Jawitz, W. J., Kumar, R., Rao, P. S. C., \& Borchardt, D. (2019a). Spatial organization of human population and wastewater treatment plants in urbanized river basins. Water Resour. Res., 55(7), 6138-6152. doi:10.1029/2018WR024614.

Yang, S., Büttner, O., Kumar, R., Jäger, C. G., Jawitz, J. W., Rao, P. S. C., \& Borchardt, D. (2019b). Spatial patterns of water quality impairments from point source nutrient loads in Germany's largest national River Basin (Weser River). Sci. Total Environ., 697, 134145. doi:10.1016/j.scitotenv.2019.134145.

Yang, S., Bertuzzo, E., Borchardt, D., \& Rao, P. S. C. (2021). Hortonian scaling of coupled hydrological and biogeochemical responses across an intensively managed river basin. Frontiers in Water, 3(97). doi:10.3389/frwa.2021.693056. 


\section{Supporting Information}

\section{Text S1.}

We characterized the streamflow regime at every points receiving WWTP-effluents along the river network by means of the persistency index $\varphi$ (Botter et al., 2013), a wellestablished metric to summarize the long-term streamflow dynamics which was shown to control several riverine environmental processes (e.g., Doulatyari et al., 2014; Basso et al., 2015). In this concept, the river flow regime is distinguished into erratic or persistent by the shape parameter $\varphi$ of a gamma distribution used to describe the probability density function of daily streamflow, $\mathrm{p}(\mathrm{Q})$ (Botter et al., 2007). The parameter is here estimated through calibration on the streamflow series simulated by the mHM (Santos et al., 2018). Values of $\varphi>1$ indicate persistent regimes characterized by weak variability around the mean streamflow, typically occurring in humid climates with rather constant rainfall and slow catchment response time. Conversely, $\varphi<1$ indicate erratic regimes displaying pronounced streamflow variability, which occur in drier climates and result from irregular rainfall and fast catchment response time (Botter et al., 2013). The persistency index under the two analyzed climatic conditions (reference and far future scenarios, see Sec. 2.3) are termed as $\varphi$ нт and $\varphi F F$, respectively. In this study, the spatial distribution of the ratio between $\varphi F F$ and $\varphi$ H is used to describe the shift of the hydrological regimes driven by climate change in the three selected catchments.

\section{Text S2.}

The algorithm aimed to identify the most reasonable river discharge simulation data for a reach receiving effluents of a given WWTP in terms of stream-orders. Key principles were set as minimizing the discrepancy in stream-orders driven from two independent datasets on river networks and simultaneously maximizing the spatial adjacency between a WWTP and a grid of simulated discharge. Suppose that a receiving stream of the i-th WWTP

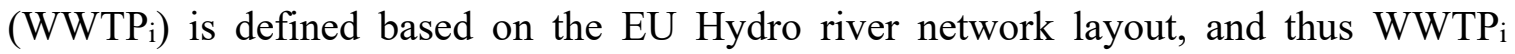
discharges to a reach with stream-order of $\omega_{\mathrm{EH}, \mathrm{i}}$. Independently, assumed that $\mathrm{WWTP}_{\mathrm{i}}$ is located within the $z$-th $\mathrm{mHM}$-grid of which stream-order is $\omega_{\mathrm{mHM}, \mathrm{z}}$. The difference between the two stream-orders, $d_{i, z}=\operatorname{abs}\left(\omega_{\mathrm{EH}, \mathrm{i}}-\omega_{\mathrm{mHM}, \mathrm{z}}\right)$, acts as the first indicator in the following sequential conditional steps: (1) If $d_{i, z}<2$, refer to the river discharge data simulated at the $z$-th grid; Otherwise, calculate the difference in stream-orders with individual 8 neighboring cells of the $z$-th grid ( $\left.\omega_{\mathrm{mHM}, \mathrm{zn} ;} n=1 \sim 8\right)$, as $\mathrm{d}_{\mathrm{i}, \mathrm{zn}}=\mathrm{abs}\left(\omega \mathrm{EH}, \mathrm{i}-\omega_{\mathrm{mHM}, \mathrm{zn}}\right)$, (2) If $\mathrm{d}_{\mathrm{i}, \mathrm{zn}}>1$ for all 8 cases of $n$, exclude the $i$-th WWTP from the analyzed subjects to reduce the uncertainty of results; Otherwise search for all cases of $n$ which results in $\mathrm{d}_{\mathrm{i}, \mathrm{zn}}<2$, as $n^{*}$ out of $n$, (3) For individual values of $n^{*}$, calculate the Euclidian distance between the $i$ - 
th WWTP location and the central coordination of the $z n^{*}$-th grid. Next, select the value of $n^{*}$ resulting the minimum distance, as $n^{*}{ }_{\min }$. Finally, refer to the river discharge data simulated at the $z n^{*}$ min -th grid.

\section{Text S3.}

Hydrological regimes in far future under the projected climate change scenario were distinct among the three river basins (Fig. S1 in SI). The Elbe River was expected to be under drier hydrological regime compared to the other two rivers. Median value of $\varphi F F$ in the Elbe (1.7) was significantly smaller than that for the Rhine and the Weser (2 and 2.1, respectively) at the $1 \%$ significance level (Kruskal-Wallis test). The fraction of $\varphi_{F F} \leq 1$ out of total $\varphi_{F F}$ points for a given river basin was the largest for the Elbe (22\%) compared to the others ( $9 \%$ for the Rhine, and $3 \%$ for the Weser). Across the three river basin, a belt of relatively drier regimes (i.e., $\varphi_{F F} \leq 2$ ) was characterized with a shape of upward-pointing triangle (Fig. S1 in SI). The belt was aligned with the boundary between two representative ecoregions in Germany: Central highlands with altitude ca. 200-800 m and Central plains with altitude $<200 \mathrm{~m}$. Given the ecoregions are equivalent to the categories to differentiate surface water types of streams in the EU Water Framework Directive (Büttner et al., 2020), the visible belt suggested higher potentials to lose aquatic ecosystems in the transient zone of ecoregions under climate change.

Besides the static snapshot of the hydrological regimes in the far future, the three rivers showed noteworthy differences in the changing characters of the hydrological regimes compared to ones estimated for the historical period (Fig. S6 in SI). Among the three rivers, the Rhine River experienced the most decrease of $\varphi_{F F}$ by a median factor of 0.86 compared to for the Rhine at the $1 \%$ significance level (Kruskal-Wallis test). The finding may be attributable to unique contribution of meltwater from the Alps to hydrological regime in the Rhine basin. Observed data and model simulations present consistent decrease of glacial mass balance, as air temperatures have risen for the last several decades, resulting the profound reduction of the snowmelt and glacier ice melt component for streamflow in the future under changing climate conditions (Junghans, 2011; Synthesis report 2016; Lobanova 2018). Comparing between the Elbe and the Weser, there were no significant difference in the distributions of $\varphi_{\mathrm{FF}} / \varphi_{\text {Нт }}$ at the $1 \%$ significance level (Kruskal-Wallis test), although the Elbe reported $\sim 3$ times larger interquartile range of $\varphi_{F F} / \varphi_{\text {нт. }}$. This consistently reflected that no source contribution of glacial or snow melt to streamflow in the two rivers. 


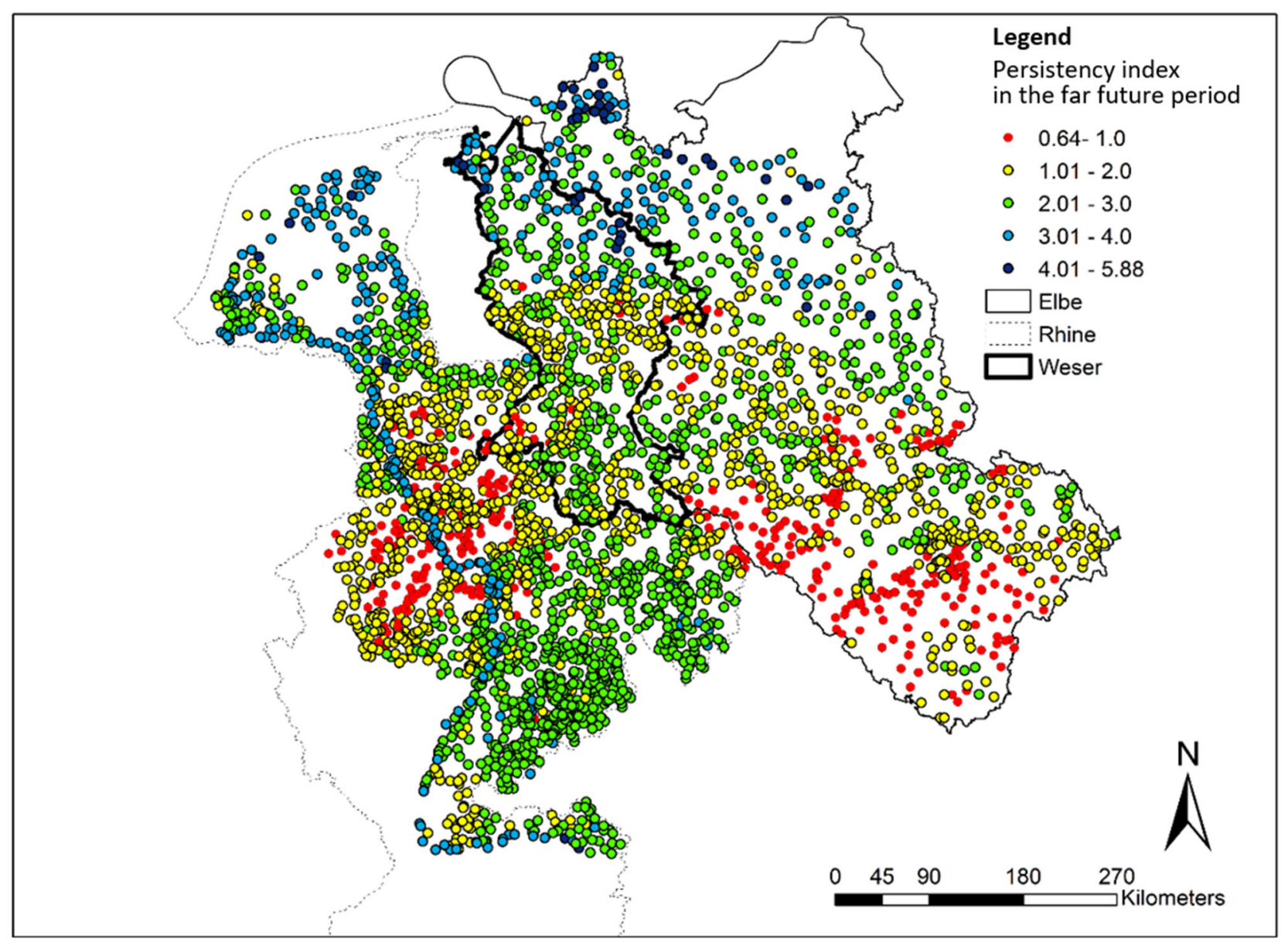

Figure S1. Presentation of the persistency index ( $\phi)$ characterizing the streamflow hydrological regime over the studied Rhine, Elbe, and Weser catchments in Central Europe. Color in each dot meaning a WWTP represents a category of the persistency index as erratic (red) or persistent (the others). Gradient of persistent level increases from yellow to dark-blue. Data and methods to derive the persistency index are given in Section 2.3 and Text $\mathrm{S} 1$ in SI, respectively. 


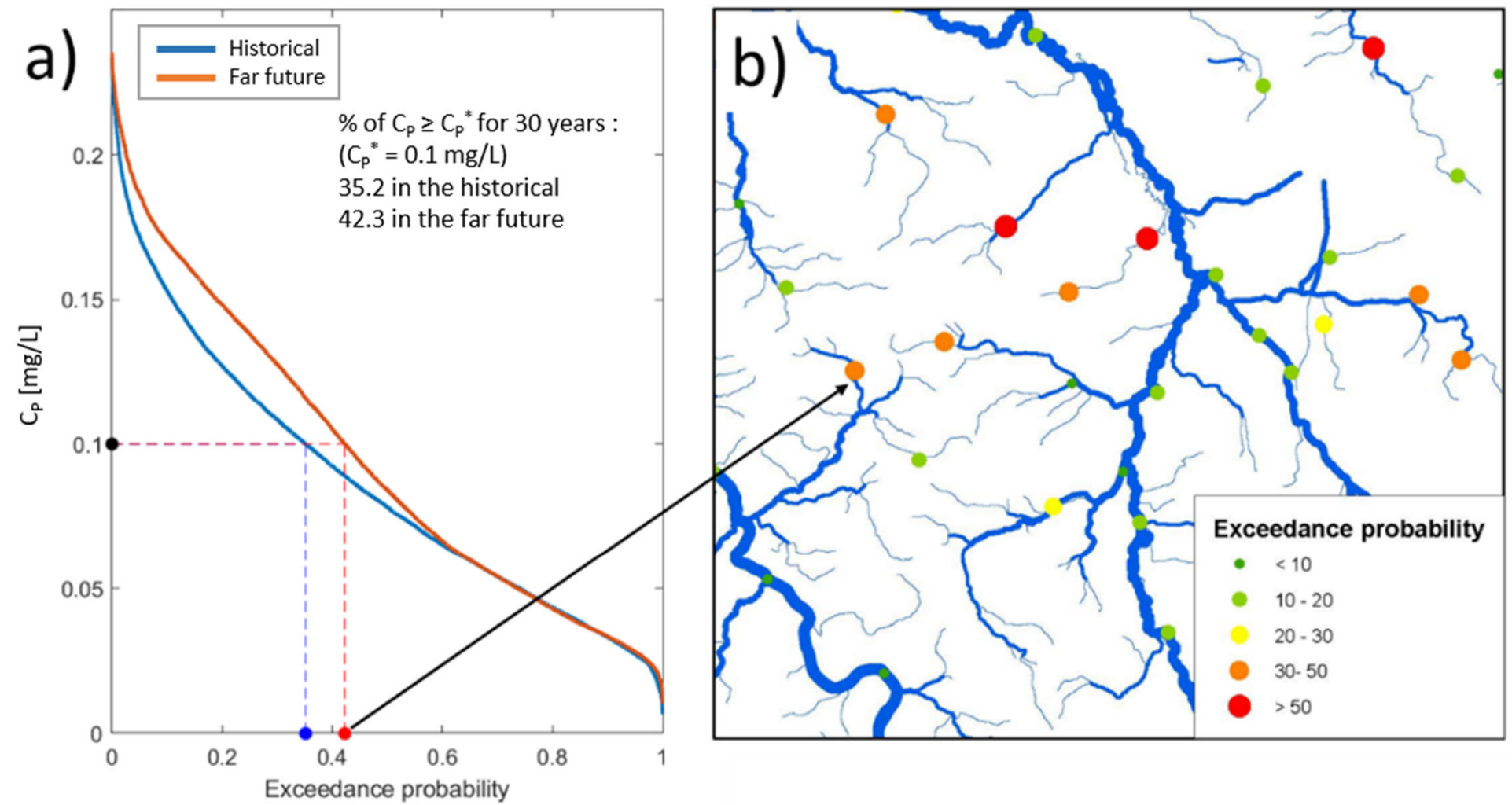

Figure S2. Principal steps for obtaining the information for filling the $k$ - $\omega$ framework illustrated for total phosphorus.

(a) For each WWTP, the exceedance probability distribution of the local-scale concentration for total phosphorus ( $\left.C_{P}\right)$ is estimated on the basis of simulated 30-year daily time-series of river discharge for the historical and far future periods. The exceedance probability for each period is calculated when the calculated $C_{p}$ matches the desirable threshold to be Good-Ecological-Status (here $C_{P}^{*}=0.1 \mathrm{mg} / \mathrm{L}$ for total phosphorus concentration).

(b) A part of spatial map showing how the calculated exceedance probability is visualized for individual WWTPs over river networks. 

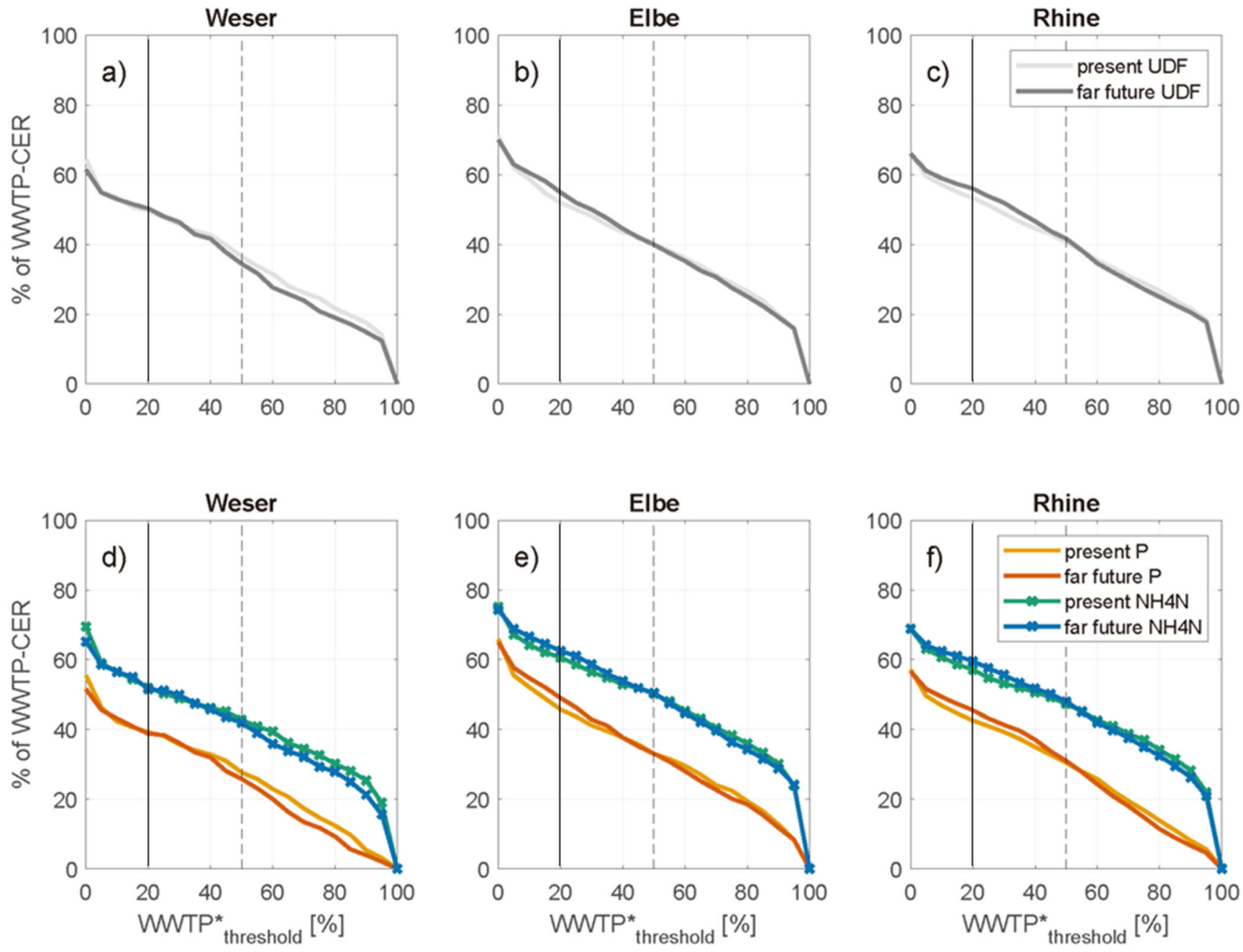

Figure S3. Varying \% of WWTPs causing ecological risk for a given threshold to define the risk-status (WWTP* threshold) ( $a-c)$ for UDF and (d-f) P and $\mathrm{NH} 4 \mathrm{~N}$ concentrations by each river basin. Results for two different simulation periods (historical and far future) are plotted together. Results based on the $W W T P^{*}{ }_{\text {threshold }}=50$ (a dashed line) and WWTP* ${ }_{\text {threshold }}=20$ (a solid line) were presented in main figures and Figs. S4-S5, respectively. 
a)

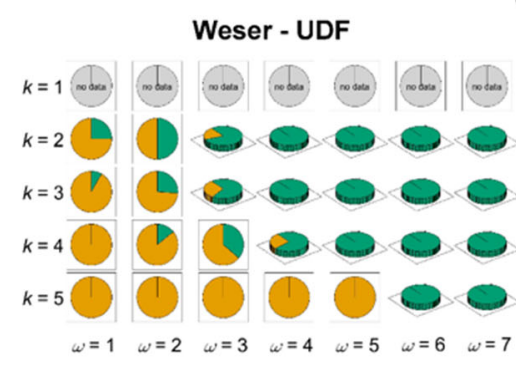

d)

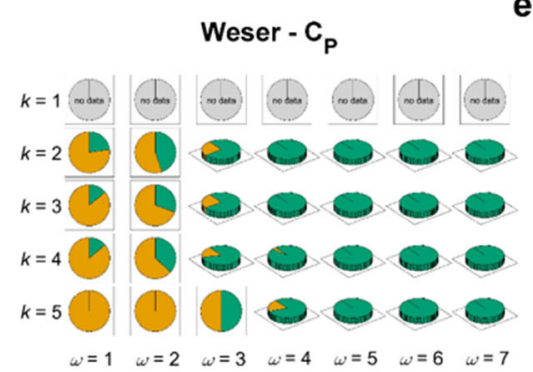

g)

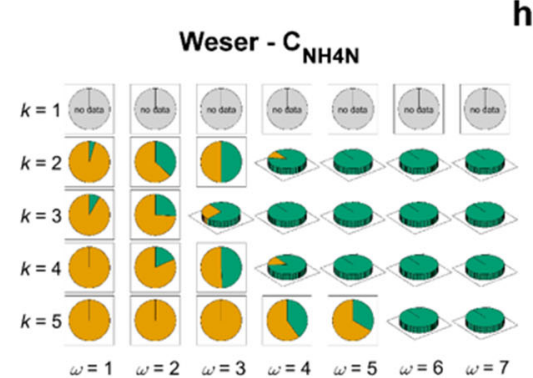

b)

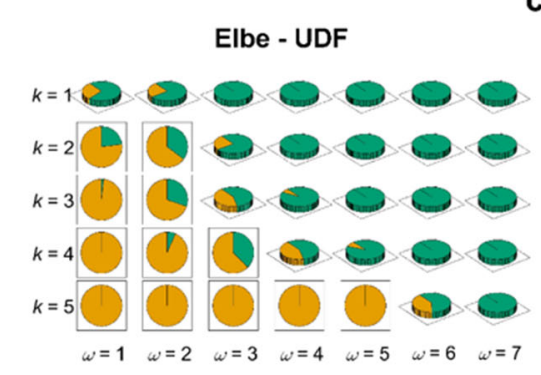

e)

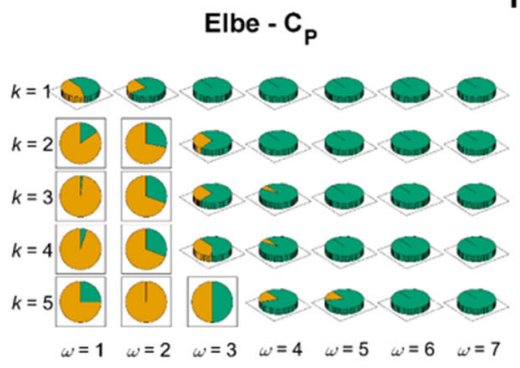

)

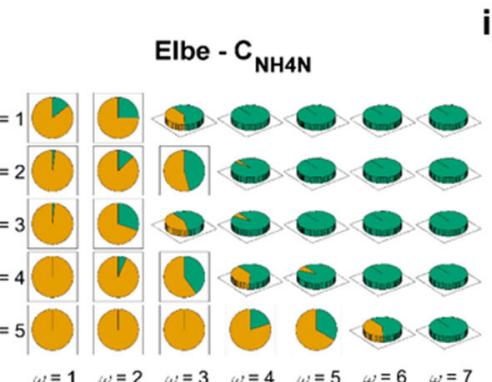

c)

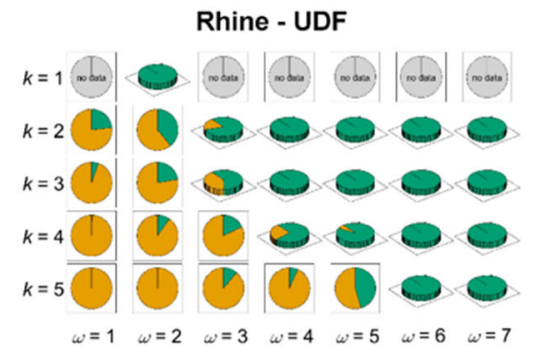

f)

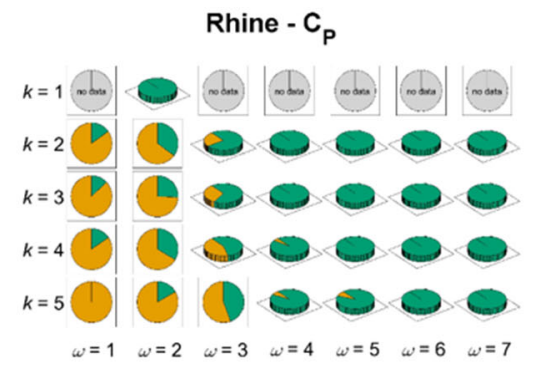

i)

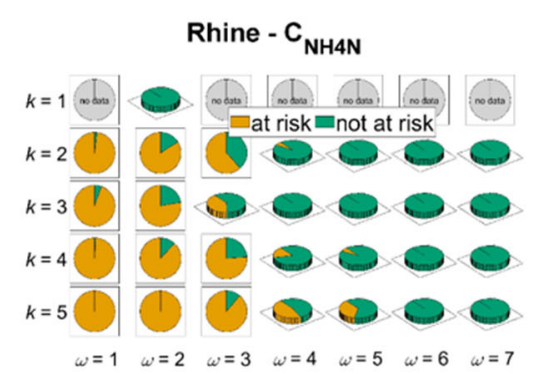

Figure S4. The $k$ - $\omega$ framework representation under the risk-threshold of WWTP* ${ }_{20}$ for all proxy indicators estimated from a given WWTP-effluent estimated with $\gamma=90$ th and $\varepsilon=10$ th percentiles at the local-scale under the far future scenario. For the three river basins, the risk-assessments for UDF, P and NH4N concentrations at the local-scale are presented as the WWTP-CER (Causing Ecological Risk) in orange and the opposite case in green. The framework consists of river stream-order $\omega$ in the absciss $a$ and WWTP-size $k$ in the ordinate. With the same color-codes of two status, WWTP-CER $<50 \%$ of total is depicted as 2-D pie, and the opposite case as 3-D pie for three environmental indicators by each river basin. 
a)

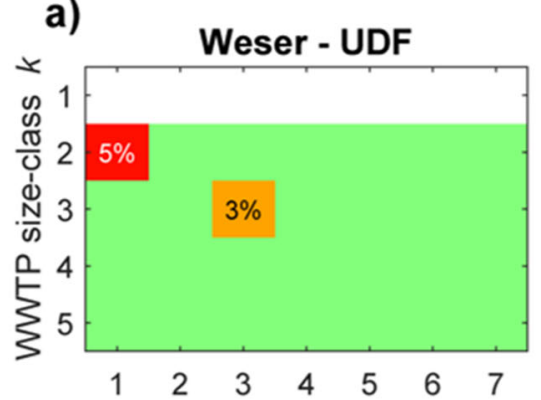

b)

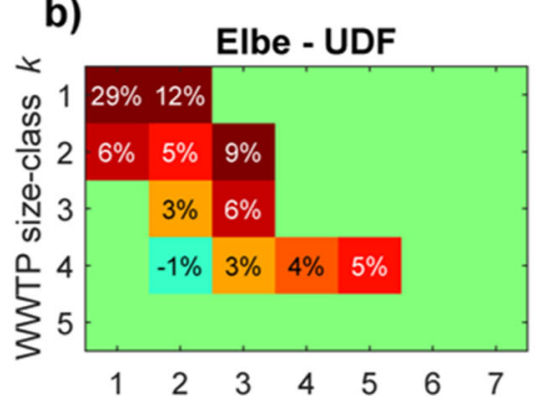

c)

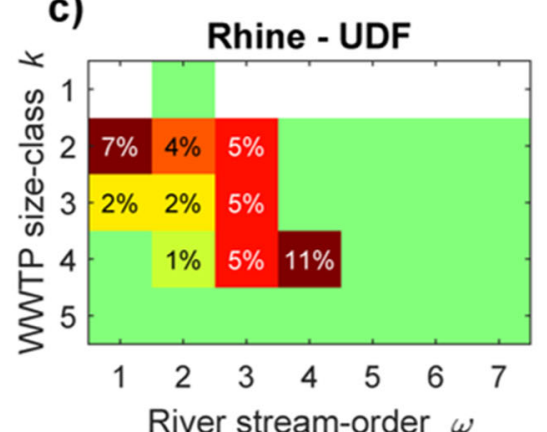

d)

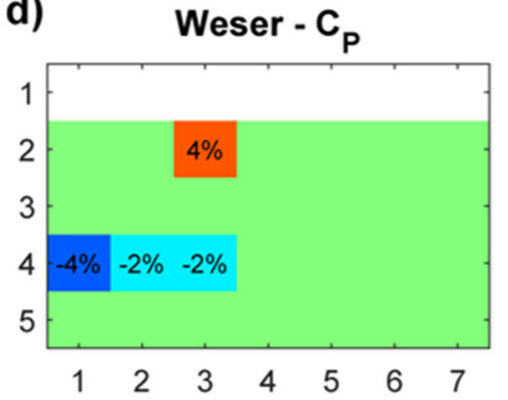

e)

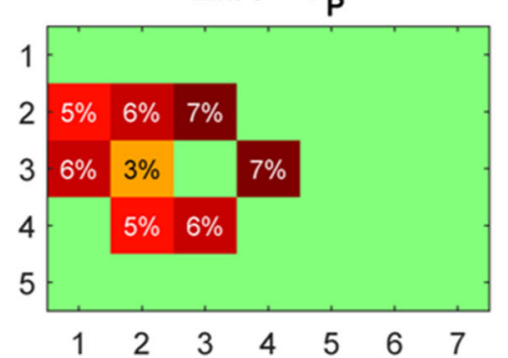

f)

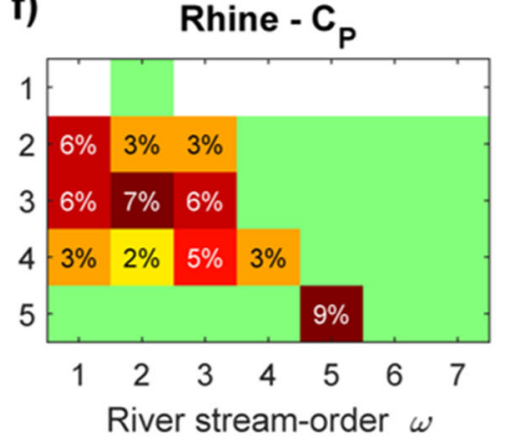

g) Weser - $\mathrm{C}_{\mathrm{NH} 4 \mathrm{~N}}$

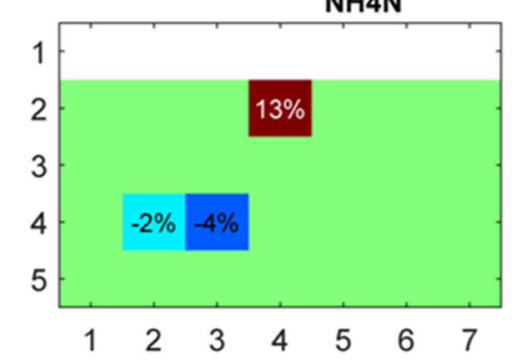

h)
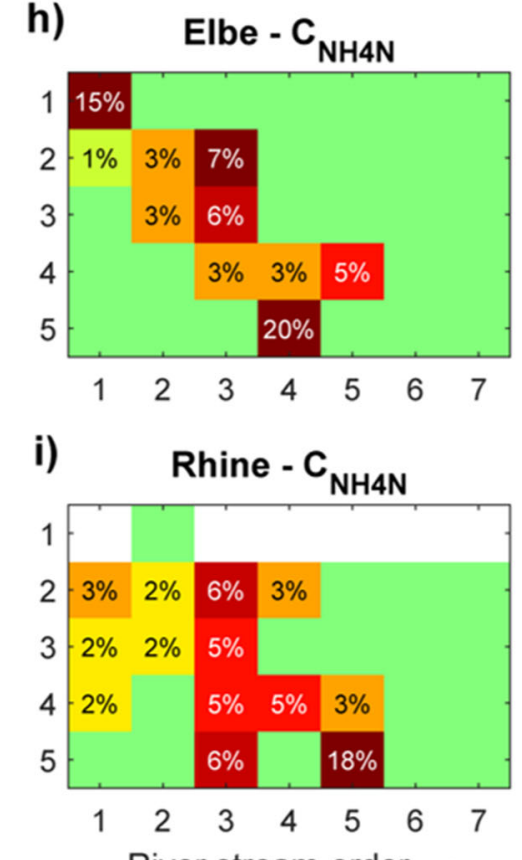

Figure S5. Changed \% of WWTP-CER from historical to the far future scenario at the local-scale based on WWTP*20 threshold. Each \% in difference was distributed by stream-order $\omega$ in the abscissa and by WWTP-size $k$ in the ordinate for three environmental indicators in each river basin.

Presented results were based on the WWTP-effluents estimated with $\gamma=90$ th and $\varepsilon=10$ th percentiles. 


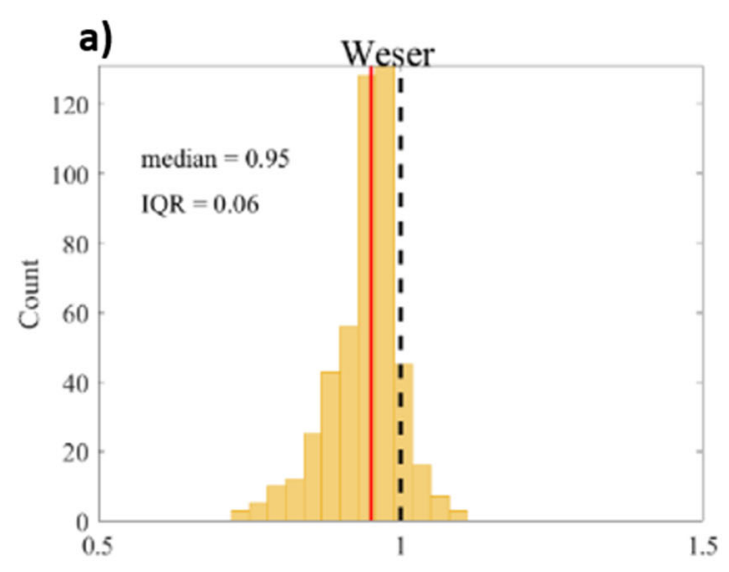

$\phi_{\mathrm{FF}} / \phi_{\mathrm{HT}}$

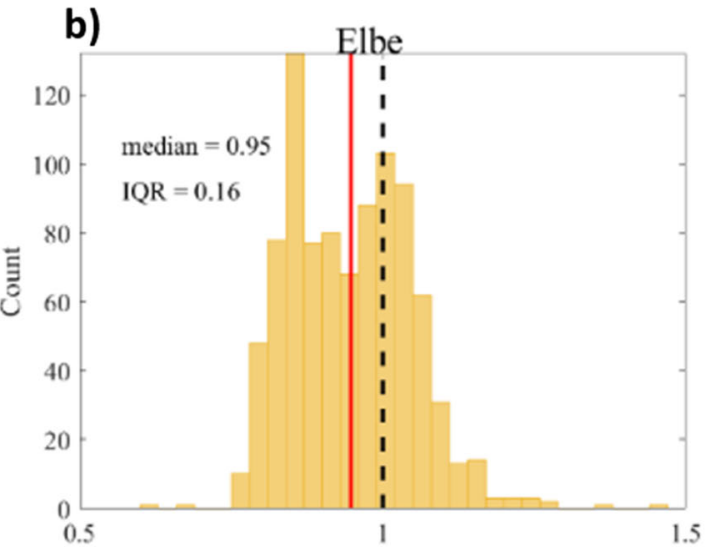

$\phi_{\mathrm{FF}} / \phi_{\mathrm{HT}}$

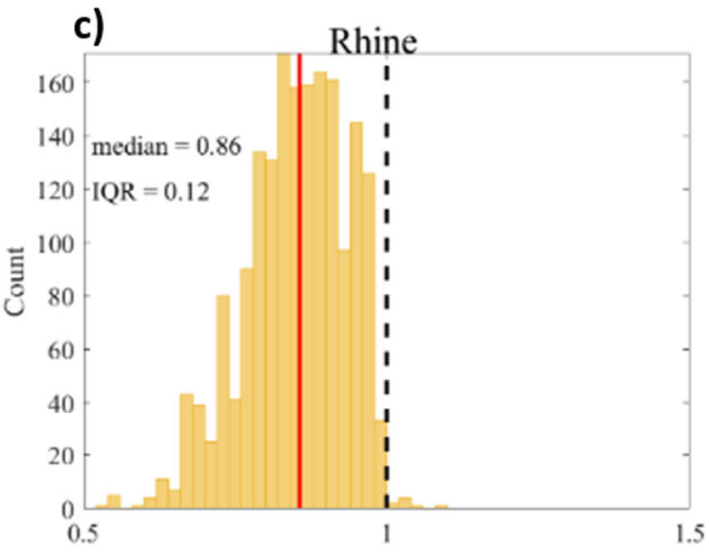

$\phi_{\mathrm{FF}} / \phi_{\mathrm{HT}}$

Figure S6. Comparison of the persistency index ( $\phi$ ) for the historical and far future periods ( $\phi_{\text {нт }}$ and $\phi_{F F}$, respectively) was conducted as the relative index $\phi_{F F} / \phi_{H T}$. (a-c) Histogram of $\phi_{F F} / \phi_{H T}$ for the Weser, Elbe, and Rhine catchments, respectively. Values of median (red line) and interquartile (IQR) range are inserted. Meaning of $\phi_{F F} / \phi_{H T}>1$ is to be wetter in the far future, while the opposite case is to be drier in the far future. 